(C) (C) 2016 IEEE. Personal use of this material is permitted. Permission from IEEE must be obtained for all other uses, in any current or future media, including reprinting/republishing this material for advertising or promotional purposes, creating new collective works, for resale or redistribution to servers or lists, or reuse of any copyrighted component of this work in other works.

This is the authors' post-print version of the journal paper published in IEEE JOURNAL OF SELECTED TOPICS IN APPLIED EARTH OBSERVATIONS AND REMOTE SENSING. Citations to this paper should be as follows: A. Alonso-Arroyo1, A., A. Monerris, C., J.P. Walker2R. Onrubia, J. Querol, H. Park, D.

Pascual, "On the Correlation Between GNSS-R Reflectivity and L-Band Microwave Radiometry," IEEE J. Sel. Top. Appl. Earth Obs. Remote Sens., vol. 9, no. 12, 2016. doi: 10.1109/JSTARS.2016.2588281 


\title{
On the Correlation Between GNSS-R Reflectivity and L-Band Microwave Radiometry
}

\author{
A. Alonso-Arroyo ${ }^{1}$, Student Member, IEEE, A. Camps ${ }^{1}$, Fellow, IEEE, A. Monerris ${ }^{2}$, C. Rüdiger ${ }^{2}$, Senior \\ Member, IEEE, J.P. Walker ${ }^{2}$, Senior Member, IEEE, R. Onrubia ${ }^{1}$, Student Member, IEEE, J. Querol ${ }^{1}$, Student \\ Member, IEEE, H. Park ${ }^{1}$, Member, IEEE, and D. Pascual ${ }^{1}$, Student Member, IEEE
}

\begin{abstract}
This work compares microwave radiometry and Global Navigation Satellite Systems-Reflectometry (GNSS-R) observations using data gathered from airborne flights conducted for three different soil moisture conditions. Two different regions are analyzed, a crops region and a grass-land region. For the crops region the correlation with the $I / 2$ (First Stokes parameter divided by two) was between 0.74-0.8 for large incidence angle reflectivity data $\left(30^{\circ}-50^{\circ}\right)$, while it was between $0.51-0.61$ for the grass-land region and the same incidence angle conditions. For the crops region the correlation with the $I / 2$ was between 0.64 0.69 for lower incidence angle reflectivity data $\left(<30^{\circ}\right)$, while it was between 0.41-0.6 for the grass-land region. This indicates that for large incidence angles the coherent scattering mechanism is dominant, while the lower incidence angles are more affected by incoherent scattering. Also a relationship between the reflectivity and the Polarization Index (PI) is observed. The PI has been used to remove surface roughness effects, but due to its dependence on the incidence angle only the large incidence angle observations were useful. The difference in ground-resolution between microwave radiometry and GNSS-R and their strong correlation suggests that they might be combined to improve the spatial resolution of microwave radiometry measurements in terms of brightness temperature and consequently soil moisture retrievals.
\end{abstract}

Index Terms-GNSS-R, Microwave radiometry, Soil moisture, Coherent reflectivity, Brightness temperature.

\section{INTRODUCTION}

$\mathbf{M}$ ICROWAVE radiometry is a passive remote sensing technique based on sensing the microwave radiation that is emitted by a body that is above $0 \mathrm{~K}$. This so-called brightness temperature is a function of the body physical temperature and the emissivity. Microwave radiometers are instruments that measure very accurately the brightness temperature, they are not highly affected by surface conditions (roughness) and they are not highly sensitive to signal noise. The spatial resolution of this technique depends on the antenna footprint and on the distance to the body under observation. In other words, the larger the antenna, the better the resolution. From the brightness temperature measurement geophysical parameters such as soil moisture can be inferred with an accuracy of $4 \%$ or better for some spaceborne missions [1], [2]. Some examples are the Soil Moisture Ocean Salinity (SMOS) [2] and the Soil Moisture Active and Passive (SMAP)

\footnotetext{
${ }^{1}$ Department of Signal Theory and Communications, Universitat Politècnica de Catalunya - BarcelonaTech (UPC) \& IEEC/UPC, Barcelona, Spain, e-mail: alberto.alonso.arroyo@tsc.upc.edu.

${ }^{2}$ Department of Civil Engineering, Monash University, Melbourne, Australia, e-mail: alessandra.monerris@gmail.com.
}

[3] spaceborne missions, both with the goal of measuring soil moisture.

Radar scatterometers measure the normalized radar cross section by transmitting a pulse towards the surface under observation, measuring the power of the back-scattered echo, and removing the noise power contribution. They work in a real aperture measurement mode. Differently from microwave radiometers, they belong to the active remote sensing family as they transmit the signal that is reflected on the surface. The spatial resolution of this technique depends on the the Doppler filtering and the geometry of observation in the across-track direction, and on the the platform's speed and the integration time in the along-track direction [4], [5]. From the radar cross-section measurement the geophysical parameters are inferred. One example is the Advanced SCATterometer (ASCAT) scatterometer that has been used like microwave radiometers for soil moisture monitoring [6], [7], and more often for sea surface wind estimation [8], [9].

Global Navigation Satellite Systems (GNSS)-Reflectometry (GNSS-R) is an emerging technique based on sensing the forward scattered GNSS signals emitted worldwide. These signals are called opportunity signals, as they are always available. GNSS-R can be seen as a passive bistatic scatterometer as GNSS-R payloads only receive the GNSS reflected signals and they do not transmit any signal. The spatial resolution of GNSS-R products depends on the surface characteristics, whether the coherent or the incoherent scattering component is dominating. Note that GNSS-R works in a forward scattering geometry where both scattering components are present [10]. As it will be later detailed, when the coherent component dominates the spatial resolution corresponds to the First Fresnel zone [11]. When the incoherent component dominates GNSS-R can also be seen as an scatterometer in the main cell of the Delay-Doppler Map (DDM), and as an unfocused Synthetic Aperture Radar (SAR) with a typical integration time of $1 \mathrm{~ms}$ (duration of the Global Positioning System (GPS) C/A code) in the outer Delay-Doppler cells [12], [13]. Therefore, in the incoherent regime it will depend on the same parameters than a scatterometer. In terms of accuracy of the retrieval it performs worse than microwave radiometers, due to its higher sensitivity to surface roughness [11], [14]. The measured reflectivity and the bistatic radar cross section, have been both correlated against the surface soil moisture obtaining significant correlation values [11], [14], [15], and they have been used to measure sea surface wind speed like conventional scatterometers [16]. 
This work compares the performance of L-Band microwave radiometry and GNSS-R, as they are techniques very close in frequency $(1.4 \mathrm{GHz}$ for microwave radiometry and $1.575 \mathrm{GHz}$ for the L1/E1/B1 frequency band used in the GPS, Galileo, and Beidou systems respectively). The first publication stating some correlation between GNSS-R and L-band microwave radiometry appeared in 2006 [17], but only qualitative relationships have been shown until now. Other works comprising other sensors comparing L-band brightness temperature and radar back-scattering cross-sections have been also performed [18], in this case including both qualitative and quantitative results. However, results presented in this manuscript suggest that the bistatic geometry provides higher correlations among those datasets.

The correlation results between both techniques leads to a possible combination of the two techniques for spatial resolution enhancement of microwave radiometry data (brightness temperature, and consequently their estimated parameters such as soil moisture). In order to enhance the spatial resolution of microwave radiometry products two different approaches have been followed. The first approach is based on image deconvolution and the application of signal processing techniques [4], [19]-[21]. For instance in [19] a factor of 1.8 spatial resolution enhancement is found for the SMOS brightness temperature images. The other approach to spatial resolution enhancement is by pixel disaggregation and the use of information of different sensors working at different frequency bands [22][24]. This approach is the one that could be followed to merge GNSS-R and L-band microwave radiometry data. Even though it provides a worse resolution than previous approaches, since GNSS-R spatial resolution is worse than optical sensors, GNSS-R data is not weather dependent while optical data is. Furthermore, this approach would be using two techniques very close in frequency, and consequently, sensitive exactly to the same geophysical parameters.

The work is structured as follows. Section II provides a summarized theoretical background. Section III shows the setup and instrumentation of the three airborne field campaigns performed under different soil moisture conditions. Section IV provides an analysis of all the datasets used (radiometry and GNSS-R), together with a comparison among them, and the main results achieved. Section V discusses the results obtained from the comparison among GNSS-R reflectivity and L-band brightness temperature. Finally, section VI summarizes the main conclusions of this work.

\section{THEORETICAL BACK-GROUND: OVERVIEW OF GNSS-R AND MICROWAVE RADIOMETRY}

\section{A. GNSS-R}

GNSS-R is an emerging technique that started in 1988, originally proposed for multistatic scatterometry [10], and continued in 1993 [25], when it was proposed to use satellite reflected navigation signals for mesoscale altimetry. In 1994, a publication reporting an 1991 aircraft incident showed the possibility of sensing navigation signals reflected over the ocean [26]. In 2000, some ground-based scatterometry experiments demonstrated that there was a relation between the GNSS scattered power and the Soil Moisture (SM) content [27]. Subsequently, the main work was developed by Masters et al. [28], but no clear relation between scattered power or Signalto-Noise Ratio (SNR) and SM was established [11], [15]. Egido et al. [14], [29] reported relations between the SM and the cross-polar scattered power. They also related the crosspolar scattered power, and the ratio between cross-polar and co-polar scattered power to SM and vegetation biomass [14]. New research towards cost-effective applications has been conducted, including the development of the Light Airborne Reflectometer for GNSS Observations (LARGO) instrument [30].

GNSS scatterometry for soil moisture monitoring is based on sensing the power of the GNSS reflected signals. The received power for each satellite can be divided into two different terms, the coherent power $\left(\mathrm{P}_{\mathrm{c}}\right)$ and the incoherent power $\left(\mathrm{P}_{\mathrm{i}}\right)$. From the bistatic radar equation the coherent received power is [31]:

$$
\mathrm{P}_{\mathrm{c}}=P_{q}^{t} \frac{\left|K_{p q}\right|^{2} \lambda^{2}}{(4 \pi)^{2}\left(r_{0 r}+r_{0 t}\right)^{2}}\left|r_{p q}\left(\theta_{i}\right)\right|^{2},
$$

where $P_{q}^{t}$ is the transmitted power by the satellite, the term $\left|K_{p q}\right|^{2} /\left((4 \pi)^{2}\left(r_{0 r}+r_{0 t}\right)^{2}\right)$ accounts for free space propagation losses, antenna gain and polarization mismatch factor $\left(\left|K_{p q}\right|^{2}\right), \lambda$ stands for the wavelength, $r_{0 r}$ is the distance between the reflection point and the receiving antenna, $r_{0 t}$ is the distance between the GNSS satellite and the reflection point, $\left|r_{p q}\left(\theta_{i}\right)\right|^{2}$ is the terrain's reflectivity which is normally modeled by the Fresnel reflection coefficients [32], $p$ stands for the transmitted polarization, and $q$ for the received polarization. In the same way the incoherent scattered power is expressed by [31]:

$$
\mathrm{P}_{i, p q}=P_{q}^{t} \frac{\left|K_{p q}\right|^{2}}{(4 \pi)^{3}} \lambda^{2} \int_{A_{i l l}} \frac{\sigma_{p q}^{0}(x, y) g_{p}^{r}(x, y) g_{q}^{t}(x, y)}{r_{r}^{2}(x, y) r_{t}^{2}(x, y)} d x d y
$$

where $\sigma_{p q}^{0}(x, y)$ stands for the incoherent bistatic scattering cross-section, $g_{q}^{r}(x, y)$ for the receiving antenna gain at $q$ polarization, $g_{p}^{t}(x, y)$ for the transmitting antenna gain at $p$ polarization, $r_{r}^{2}(x, y)$ for the distance between each scatterer and the receiving antenna, and $r_{t}^{2}(x, y)$ for the distance between each scatterer and the transmitting antenna. The amount of coherent or incoherent power will depend basically on the surface roughness condition and the scattering geometry (incident and specular reflection angles) [33]. The thermal noise power reaching the receiver after the correlation with a locally-generated replica of the transmitted code (conventional GNSS-R or cGNSS-R in short) is:

$$
P_{N}=k\left(T_{a n t}+T_{0} \cdot(F-1)\right) B_{c o h},
$$

where $k$ stands for the Boltzmann constant, $T_{\text {ant }}$ for the antenna noise temperature, $T_{0}=290 \mathrm{~K}, F$ is the system noise figure, and finally $B_{c o h}$ which is the equivalent noise bandwidth, which corresponds to the inverse of the coherent integration time $\left(1 / T_{\text {coh }}\right)$.

The spatial resolution of GNSS-R varies depending on the reflection conditions. For the coherent reflected power, 
the spatial resolution corresponds to the first Fresnel zone [11], [15]. For the incoherent power, it corresponds to the so called glistening zone [34], which is limited by the scattering properties and some system parameters such as the coherent integration time $T_{c o h}$ and the code modulation used. Furthermore, depending on the Delay-Doppler cell looked, the incoherent scattered power has a different spatial resolution [12], [13], whereas the coherent one always comes from the same region of the DDM [34]. However, for the land scattering case, due to the low reflectivity of land in comparison to water, values out of the first iso-delay cell are very small, and therefore not reliable unless a very large incoherent integration time is used.

\section{B. Microwave radiometry}

L-Band Microwave radiometry is a consolidated remote sensing technique to measure soil moisture [35], [36]. It is based on measuring the terrain's emissivity $e$, which is $1-R$, being $R$ the terrain's reflectivity. The terrain's reflectivity has two different parts, a coherent component and an incoherent one. The coherent one is modeled by the Fresnel reflection coefficients, and the incoherent one using the scattering cross section. Coherent reflectivity is defined as the modulus square of the Fresnel reflection coefficients. In this model, surface roughness is characterized by its standard deviation $\left(\sigma_{r m s}\right)$, and then the Fresnel coherent reflectivity $\left(R_{c, p q}(\theta)\right)$ is corrected by an attenuation factor, also known as the Rayleigh attenuation parameter:

$$
R_{c, p q}\left(\theta_{i}\right)=\left|r_{p q}\left(\theta_{i}\right)\right|^{2} e^{-\left(2 \kappa \sigma_{r m s} \cos \left(\theta_{i}\right)\right)^{2}}
$$

where $\kappa$ stands for the wavenumber. Incoherent reflectivity $\left(R_{\text {inc }}\right)$ is expressed using the scattering cross-section as [37]:

$R_{i n c}\left(\theta_{i}, \phi_{i}\right)=\frac{1}{4 \pi} \int_{4 \pi}\left[\sigma_{p p}^{0}\left(\theta_{i}, \phi_{i}, \theta_{r}, \phi_{r}\right)+\sigma_{p q}^{0}\left(\theta_{i}, \phi_{i}, \theta_{r}, \phi_{r}\right)\right] d \Omega$

where $i$ and $r$ stand for the incident and reflected radiation respectively, $\theta_{i}$ for the incidence angle, $\phi_{i}$ for the azimuth angle, $\sigma_{p p}^{0}$ for the co-polar bistatic scattering cross section, and $\sigma_{p q}^{0}$ for the cross-polar bistatic radar cross section. However, modeling errors in the bistatic radar cross section simulation and generation, and the computation of the whole integration is not practical. In that case, for smooth surface terrains, it is assumed that the equivalent incoherent reflectivity is much smaller than the coherent one. Consequently, it is not taken into account in the emissivity models, and emissivity reduces to the use of the coherent reflectivity component. Thus, emissivity at horizontal and vertical polarizations are $e_{H}\left(\theta_{i}\right)=1-R_{c, H H}\left(\theta_{i}\right)$ and $e_{V}\left(\theta_{i}\right)=1-R_{c, V V}\left(\theta_{i}\right)$, respectively.

A microwave radiometer measures the noise power emitted by the terrain in a frequency band of the microwave spectrum. The power measured by a radiometer depends basically on 3 parameters: the Boltzmann constant $(k)$, the system Bandwidth $(B)$, and the antenna temperature, which is then related to the so called Brightness Temperature $\left(\mathrm{T}_{B}\right)$ taking into account the System parameters. The $\mathrm{T}_{B}$ at $q$ polarization is equal to:

$$
T_{B q}=e_{q} T_{F},
$$

where $T_{F}$ is the object's physical temperature. So a calibrated microwave radiometry measurement includes also the measurement of the target physical temperature in order to obtain the emissivity parameter.

\section{Reflectivity and Emissivity curves}

For a flat surface, both the reflectivity and the emissivity depend on two parameters: the incidence angle $\left(\theta_{i}\right)$, and the soil dielectric constant $\left(\varepsilon_{r}\right)$. There are several models to obtain the soil dielectric constant as a function of the soil moisture content [38]-[41]. To illustrate the reflectivity and emissivity curves, and explain the relationship among them, the Wang's model [38] has been used for the sake of simplicity. To generate the dielectric constant as a function of soil moisture a soil composition of $50 \%$ clay, and $20 \%$ sand has been chosen.

Figures 1(a)-(d) show the reflectivity curves for a flat surface with different soil moisture values and different polarization, as a function of the incidence angle. Figure 1(a) shows the reflectivity for horizontal polarization, which is monotonically increasing with SM content. Figure 1(b) shows the reflectivity for vertical polarization is shown, which in this case is decreasing until the Brewster angle position, where there is minimum reflectivity, and then starts increasing towards 1 . Figure 1(c) shows the reflectivity for the transmitted Right Hand Circular Polarization (RHCP) polarization and reflected RHCP polarization, which is much smaller than the other ones. However, at grazing angles it is quite large and comparable to the vertical and horizontal ones. This occurs because, for an incidence angle above the Brewster angle, both components $(\mathrm{H}$ and $\mathrm{V})$ change their phase in the reflection process, and polarization is preserved. The point where the $\left|r_{R R}\right|^{2}$ starts to be noticeable is related to the Brewster angle position [42]. Figure 1(d) shows reflectivity for a transmitted RHCP wave $r$ and a reflected Left Hand Circular Polarization (LHCP) wave. This is the general case in GNSS-R scatterometry, where the transmitted polarization by GNSS satellites is RHCP to minimize Faraday rotation effects, and as it can be deduced from Figs. 1(c)-(d), the main received power is LHCP polarized. Furthermore, if roughness effect is negligible, there is one region between $0^{\circ}-45^{\circ}$ incidence angle where the reflectivity is insensitive to incidence angle variations. The emissivity at horizontal polarization is equivalent to $1-\left|r_{H H}\right|^{2}$ curve (Fig. 1(a)), and therefore monotonically increasing. In the same way, the emissivity at vertical polarization is equivalent to $1-\left|r_{V V}\right|^{2}$, and it has the inverse behavior than the reflectivity curve. Figure 1(e) shows first Stokes parameter divided by two (normalized to the physical temperature) [43]-[45], which is a combination of the $\left|r_{R L}\right|^{2}$ and $\left|r_{R R}\right|^{2}$ curves. It is understood to represent a measurement of the total incident brightness temperature at circular polarization independently from the rotation sense. From now on this parameter will be notated as $I / 2$, and it is defined as:

$$
I / 2=\frac{1}{2}\left(\mathrm{~T}_{B H}+\mathrm{T}_{B V}\right) .
$$

This is done for very flat surface areas in order to mitigate the dependence of the emissivity and/or $\mathrm{T}_{B}$ on the incidence angle. Finally, Fig. 1(f) shows the Polarization Index (PI) 
(Polarization Index) [46], [47], which is defined as:

$$
\mathrm{PI}=\frac{\mathrm{T}_{B V}-\mathrm{T}_{B H}}{\frac{1}{2}\left(\mathrm{~T}_{B V}+\mathrm{T}_{B H}\right)}=2 \frac{e_{V}-e_{H}}{e_{V}+e_{H}}
$$

The PI is interesting because it normalizes the $\mathrm{T}_{B}$ measurement, making it independent from the physical temperature. This independence from the physical temperature is very important, as it means that measurements are automatically calibrated, as they are relative.

Something mentioned before, but not shown in the examples, is the effect of surface roughness on the emissivity and reflectivity curves. Surface roughness disperses radiation which attenuates coherent reflectivity and makes the reflectivity curves closer among them (in linear units as presented in Fig. 1(a)-(d)). In the case of emissivity, its curves would rise their level, resulting in a biased brightness temperature observation. Furthermore, the emissivity curves also become closer, which means that the retrieval is less accurate.

\section{GELOZ FIELD CAMPAIGNS}

The GNSS-R Experiments over Land in Australia (GELOz) are a series of three airborne field experiments conducted between September and November of 2013. Those flights were performed under different soil moisture conditions. The LARGO scatterometer [30] was flown together with the Polarimetric L-Band Microwave Radiometer (PLMR) radiometer [48] in order to compare the data obtained with both instruments and analyze the relationship between GNSS-R and Lband microwave radiometry observations. Hot and cold load calibration of PLMR was performed before the flights. The LARGO is calibrated using direct signal measurements in the post-processing stage every second. The first flight was conducted when the average SM of a grass-land target area was $0.15 \mathrm{~m}^{3} \mathrm{~m}^{-3}$. In the second one, the terrain of the same grass-land target area was very dry with and the average soil moisture below $0.08 \mathrm{~m}^{3} \mathrm{~m}^{-3}$. The third flight was performed after a rain event on the same region in order to see the contrast between the previous scenarios. The platform's movements were measured using the aircraft's OxTS RT3003 system [49], which provided a position accuracy of $2 \mathrm{~cm}$, a roll and pitch accuracy of $0.03 \mathrm{deg}$, and a heading accuracy of $0.1 \mathrm{deg}$. Concurrent intensive $0-6 \mathrm{~cm}$ soil moisture sampling using hydraprobes is available for the first two flights over the target grass-land area in a $250 \mathrm{~m} \times 125 \mathrm{~m}$ grid. Three measurements were conducted at at each grid point in order to account for the SM spatial variability. Vegetation type and height were also recorded at each location. Apart from that, the OzNet stations data [50] are available for all flights for the grass-land target area and for another target area which was a crops area. More information about both target areas is given in section IV. The three flights followed approximately the same path over the target areas, departing from Tyabb, Victoria, Australia, and landing on a regional airport (Narrandera) close to the Yanco region, New South Wales, Australia. The flight route was designed to ensure full coverage of PLMR over the grassland area (approximately $4 \mathrm{~km} \mathrm{E-W} \mathrm{x} 1.5 \mathrm{~km} \mathrm{~N}-\mathrm{S}$ in size), and just following the location of the OzNet stations over the crops area. The overpass over nearby lakes was used to have a water body reference. Figure 2 shows the route for one of the flights, as an example.

\section{A. LARGO Scatterometer}

The LARGO scatterometer is a GNSS-R instrument designed and engineered at Universitat Politècnica de CatalunyaBarcelonaTech (UPC). It was specifically designed to measure the reflectivity of the targets illuminated by GNSS satellites. Currently, it is configured to work only with the GPS constellation and the civil/public codes (L1-CA, $1575 \mathrm{MHz}$ ). It is a dual-channel low-power passive receiver. One channel is connected to a zenith-looking RHCP antenna to monitor the direct signals, which are used in the post-processing stage for calibration purposes, and to estimate the power transmitted by GPS satellites. The second channel is connected to a nadirlooking LHCP antenna, as it is the main polarization for the reflected signals, as it was shown in Fig. 1. The instrument performs power measurements of all the reflected signals within the down-looking antenna Field of View (FOV). Power measurements on both channels were performed using $1 \mathrm{~ms}$ of coherent integration time and $1 \mathrm{~s}$ of incoherent integration time. Reflectivity was estimated using the information provided by both channels.

The ground-resolution of the LARGO instrument can be determined by its sensing properties. As it will be seen later, the LARGO instrument is sensitive to the coherent component of the reflected signal, and consequently, its ground-resolution is determined by the 1st Fresnel Zone [11]:

$$
a=\frac{\sqrt{\lambda H \cos \theta_{i}}}{\cos \theta_{i}}, b=\frac{\sqrt{\lambda H \cos \theta_{i}}}{\cos ^{2} \theta_{i}},
$$

where $a$ and $b$ are the semi-minor and semi-major axes of the first Fresnel zone ellipse projected on the ground, $\lambda$ is the wavelength, $\theta_{i}$ is the incidence angle, and $H$ the platform's height. Since this is the instantaneous ground-resolution, it is also necessary to take into account the platform's speed and the integration time in order to determine the final groundresolution. The first two flights were made at 220 meters height at a speed of $220 \mathrm{~km} / \mathrm{h}$, whereas the third flight was made at a height of 150 meters at the same speed. This leads to a ground resolution of $67 \mathrm{~m} \mathrm{x} 8 \mathrm{~m}$ for the first two flights and $66.7 \mathrm{~m}$ $\mathrm{x} 6.8 \mathrm{~m}$ for the third one, which is roughly the same for the three flights despite the height difference. The integration time lowers the achievable instantaneous ground resolution severely as will be discussed in section V-C.

\section{B. PLMR radiometer}

The PLMR is a microwave radiometer working at Lband (1400-1426 MHz) [48], [51]. It measures the brightness temperature in the range of $0-350 \mathrm{~K}$ with an accuracy of $0.7 \mathrm{~K}$ for one second of integration time. It has an $8 \times 8$ patch antenna array with vertical and horizontal polarization feeds. PLMR also uses analog beamforming to generate 6 different beams at a time pointing to $\pm 8^{\circ}, \pm 21^{\circ}, \pm 38^{\circ}$ offnadir, with an antenna beamwidth of $15^{\circ}$. The $\pm 38^{\circ}$ beams correspond to beams 1 and 6 , the $\pm 21^{\circ}$ correspond to beams 2 and 5 , and the $\pm 8^{\circ}$ correspond to beams 3 and 4 . Its size 
is $94 \times 94 \times 20 \mathrm{~cm}$ and weights approximately $40 \mathrm{~kg}$. Figure 3(a) shows an overview of the general set-up used to perform the field campaigns. Part of the LARGO setup is shown in Fig. 3(b); in particular the instrument and the direct antenna connection. Figure 3(c) shows the PLMR instrument before its installation in the aircraft's pod.

The ground-resolution of PLMR is determined by the antenna footprint projected onto the ground, the beam used (incidence angle), and the platform height. For the first two flights the ground-resolution is approximately $120 \mathrm{~m} \mathrm{x} 58 \mathrm{~m}$ for the $\pm 8^{\circ}$ beams $127 \mathrm{~m} \mathrm{x} 62 \mathrm{~m}$ for the $\pm 21^{\circ}$, and $153 \mathrm{~m} \times 93 \mathrm{~m}$ for the $\pm 38^{\circ}$. For the third flight the ground resolution is approximately $101 \mathrm{~m} \mathrm{x} 40 \mathrm{~m}$ for the $\pm 8^{\circ}$ beams $106 \mathrm{~m} \mathrm{x} 42 \mathrm{~m}$ for the $\pm 21^{\circ}$, and $110 \mathrm{~m} \mathrm{x} 63 \mathrm{~m}$ for the $\pm 38^{\circ}$. In this case the integration time does not degrade as severely the instantaneous ground-resolution. It will be seen in section $\mathrm{V}-\mathrm{C}$ that the reflectivity pixels are only $10 \%$ approximately overlapped, whereas the radiometry pixels are at least $50 \%$ overlapped. This will have an impact on the data correlation.

\section{DATA ANALYSIS}

\section{A. GNSS-R data set}

Instead of directly performing an absolute power measurement of the direct and reflected signals, the LARGO instrument measures the observed thermal SNR, which is equivalent to the power received compared to the thermal noise floor level. The measured thermal SNR for the waveform peaks for the direct/up-looking LARGO channel after the correlation with a clean replica of the satellite code is:

$$
\mathrm{SNR}_{U}=\frac{E I R P_{T} G_{R_{U}}\left(\theta_{R_{U}}, \phi_{R_{U}}\right) \rho_{R_{U}}\left(\theta_{R_{U}}, \phi_{R_{U}}\right) \lambda^{2}}{\left(4 \pi R_{U}\right)^{2} k\left(T_{a n t_{U}}+T_{0}\left(F_{U}-1\right)\right) B_{U}},
$$

where $E I R P_{T}$ stands for the Equivalent Isotropically Radiated Power transmitted by the GNSS satellites, $G_{R_{U}}$ for the receiving antenna gain, $\theta_{R_{U}}$ and $\phi_{R_{U}}$ for the incoming signal direction in the antenna reference frame, $\rho_{R_{U}}$ for the polarization mismatch factor, $R_{U}$ for the distance path traveled by the direct signal, $T_{a n t_{U}}$ for the up-looking antenna temperature, $T_{0}$ is $290 \mathrm{~K}, F_{U}$ for the receiving chain noise figure, and $B_{U}$ for the system's bandwidth after the correlation with the satellite code.

The measured thermal SNR for the reflected/down-looking channel after the correlation with the satellite code is:

$$
\mathrm{SNR}_{D}=\frac{E I R P_{T} G_{R_{D}}\left(\theta_{R_{D}}, \phi_{R_{D}}\right) \rho_{R_{D}}\left(\theta_{R_{D}}, \phi_{R_{D}}\right) \lambda^{2} R_{c, R L}\left(\theta_{i}\right)}{\left(4 \pi R_{D}\right)^{2} k\left(T_{a n t_{D}}+T_{0}\left(F_{D}-1\right)\right) B_{D}},
$$

where $G_{R_{D}}$ stands for the receiving antenna gain, $\theta_{R_{D}}$ and $\phi_{R_{D}}$ for the incoming signal direction in the antenna reference frame, $\rho_{R_{D}}$ for the polarization mismatch factor, $R_{c, R L}\left(\theta_{i}\right)$ for the coherent reflectivity, $\theta_{i}$ for the local incidence angle, $R_{D}$ for the distance traveled by the signal in the downwelling and upwelling paths, $T_{a n t_{D}}$ for the down-looking antenna temperature, $F_{D}$ for the receiving chain noise figure, and $B_{D}$ for the system's bandwidth after the correlation with the satellite code. This equation assumes that surface roughness is relatively low, and consequently, the coherent scattered component is much larger than the incoherent one. When radiometry and reflectometry data are compared the roughness limitations will be seen. Consequently, the coherent reflectivity can be estimated as:

$$
R_{c, R L}\left(\theta_{i}\right)=\frac{S N R_{D}}{S N R_{U}} \frac{G_{R_{U}} \rho_{R_{U}}}{G_{R_{D}} \rho_{R_{D}}} \frac{T_{a n t_{D}}+T_{0}(F-1)}{T_{a n t_{U}}+T_{0}(F-1)},
$$

considering that the system's equivalent bandwidth is the same for both channels, which it is because both use $1 \mathrm{~ms}$ of coherent integration, the noise figure $(F)$ is also the same for both channels, and that the distance $R_{U}$ and $R_{D}$ are practically the same for ground-based and airborne conditions. After having compensated for the different antenna gains seen by both the direct and reflected signals, the terrain's reflectivity can be estimated. This reflectivity corresponds to the coherent component, as the incoherent component is generally much lower than the coherent for the target areas. This assumption is also supported by recent data from the UK-DMC [52]-[54] and UK TDS-1 missions [16], [55].

The geolocation of the specular reflection points is done by ray tracing and assuming the paraxial approximation of rays, which means that direct signal, and the one that impinges on the terrain are parallel. This means that for a flat surface, the incidence angle $\left(\theta_{i}\right)$ is the complementary angle of the GNSS satellite elevation angle $\left(\theta_{e}\right)$. With a simple GNSS receiver obtaining the signal from a coupler on the direct channel it is therefore straightforward to perform the geo-location. For an airborne receiver, the specular reflection point for each satellite, or center of the First Fresnel zone, is:

$$
x=\frac{\left(H-H_{0}\right) \sin \phi_{a}}{\tan \left(90-\theta_{e}\right)}, y=\frac{\left(H-H_{0}\right) \cos \phi_{a}}{\tan \left(90-\theta_{e}\right)},
$$

where $x$ and $y$ coordinates are expressed in meters, and are referred to the platform position, $H_{0}$ is the geoidal separation to the WGS84, $H$ the platform height with respect to the WGS84, $\theta_{e}$ the GNSS satellite elevation angle, and $\phi_{a}$ the GNSS satellite azimuth angle. In order to geo-locate the specular reflection points for each acquisition, it is necessary to change from latitude and longitude coordinates to Universal Transverse Mercator (UTM) coordinates, add the $x$ and $y$ coordinates computed to the platform's position, and then go back to latitude and longitude coordinates ${ }^{1}$.

Once the data processing is completed as described, Figs. $4 \mathrm{a}-4 \mathrm{c}$ are produced to show the reflectivity maps obtained for a particular sub-set of the whole field campaign. They include the pass over a lake (blue region), in order to have a water body as a reference, and the Yanco area, where several flight passes were performed. The main focus area (latitude: from $35.05^{\circ}$ to $-34.9^{\circ}$, from now on grass-land) shows a reflectivity range of $-12 \mathrm{~dB}$ to $-16 \mathrm{~dB}$ (Fig. $4 \mathrm{a}$ ) for the first flight, for the second flight (Fig. 4b) reflectivity is between $-14 \mathrm{~dB}$ and $-18 \mathrm{~dB}$, and for the third flight (Fig. 4c) it ranges from $-8 \mathrm{~dB}$ to $-12 \mathrm{~dB}$. In all the flights, the reflectivity of the water body ranged from $-5 \mathrm{~dB}$ to $0 \mathrm{~dB}$. This coincides qualitatively with the experiment explanation seen in section III where the SM content for the first flight was around $0.15 \mathrm{~m}^{3} \mathrm{~m}^{-3}$, it was very dry for the second flight (less than $0.08 \mathrm{~m}^{3} \mathrm{~m}^{-3}$ ), and the third flight was performed after a rain event without intensive soil moisture ground-truth. This is also in concordance with

\footnotetext{
${ }^{1}$ This methodology is valid only for ground-based and airborne conditions as the paraxial approximation and the flat Earth model apply in those conditions. In order to geo-locate from a spaceborne point of view, it is necessary to obtain the satellite position from the almanac and ephemeris data, work with data in Earth-Centered, Earth-Fixed (ECEF) coordinates, and consider the elliptical shape of the Earth. An example of the specular point computation for spaceborne observations can be found in [56]
} 
Fig. 1 where a larger reflectivity is caused by higher levels of soil water content or even open water bodies. In particular, when observing small open inland water bodies, the reflectivity can be as large as $-1 \mathrm{~dB}$, behaving as expected very close to a mirror in the microwave L-band spectrum. Also, in the reflectivity maps it is possible to see at least two different tracks. These appear due to the different satellites in view that are monitored at the same time, which shows the multistatic properties of the GNSS-R technique [10]. The tracks are not the same in the three figures due to two main reasons: 1) the plane did not follow exactly the same flight path, 2) the satellites' positions were not the same in the three field campaigns (geometry changed).

\section{B. PLMR data set}

Figures $4 \mathrm{~d}-4 \mathrm{f}$ show the $\mathrm{H}-\mathrm{Pol}$ brightness temperature maps for the three GELOz flights. In Fig. 4d (first flight) it is easy to identify the lake that was seen on the reflectivity data, and also some other water bodies. Looking to the Yanco area, the $\mathrm{T}_{B H}$ ranges from $250 \mathrm{~K}$ to $265 \mathrm{~K}$, changing to $260 \mathrm{~K}-280 \mathrm{~K}$ for the second flight, and about $210 \mathrm{~K}$ for the third flight. This is indicative of the general surface conditions of the area, going from relatively wet to dry, and then significantly wetting up again. The same patterns are seen in the $\mathrm{T}_{B V}$ data (Figs. $4 \mathrm{~g}-$ $4 i)$.

\section{GNSS-R and Microwave Radiometry Relationship}

Qualitatively, the behavior of the reflectivity and brightness temperature data across both polarizations depending on the field conditions has been explained: when the soil moisture increases, reflectivity rises, and emissivity decreases, and consequently $\mathrm{T}_{B}$, and vice versa. Again, qualitatively, there is a negative relationship between the reflectivity maps and the $\mathrm{T}_{B}$ maps. Note that in Figs. $4 \mathrm{a}-4 \mathrm{c}$ the color scale has been inverted, to reflect this relationship and to make sure that dry surface conditions are represented in red for both types of measurements.

In the previous qualitative analysis there are several parameters that must be taken into account in order to perform a quantitative analysis and study the correlation between GNSS-R and microwave radiometry. The main parameters to take into account that may differ in both situations are:

1) Incidence angle $\left(\theta_{i}\right)$ : While for the PLMR data it is very clear and it is determined by the beam pointing direction (taking into account the platform's attitude), in GNSS-R it depends on the satellite geometry, and as discussed above it was different for the three field campaigns. This feature is seen by comparing Figs. $4 a-4 c$ where the separation between satellite tracks is different.

2) Polarization: While GNSS satellites transmit in RHCP and GNSS-R data is mainly LHCP, microwave radiometry data has been measured at linear polarization. This yields a noticeable change, as for circular polarization there is almost no dependence with the incidence angle up to $45^{\circ}$, whereas for linear polarization it is, as seen in Fig. 1. This means that it is not possible to directly compare both measurements for a quantitative analysis and as it will be seen later, linear brightness temperature measurements will be transformed into other parameters.

3) Surface roughness: The effect of surface roughness is not the same for the two types of measurements, as GNSS-R relies on the forward scattering mechanism, which is mainly based on the coherent reflection model, and microwave radiometry on the emissivity, which is an integral over half hemisphere of the co- and cross-polar bistatic scattering coefficients.

4) Land Cover: The surface coverage may have an impact on the reflectivity and $\mathrm{T}_{B} \mathrm{~S}$ measured, as it will not be the same to have bare soil, grass-land, or some crops which may have a taller vegetation and different water content.

In order to solve the first two points, $\mathrm{T}_{B H}$ and $\mathrm{T}_{B V}$ are combined to form half of the $I / 2$ and the PI, as shown in Fig. 1(e)-(f). To study the third point, the reflectivity data has been binned into two different regions: incidence angles ranging from $30^{\circ}$ to $50^{\circ}$, where the reflection is assumed to have a larger coherent part, and incidence angles ranging from $0^{\circ}$ to $30^{\circ}$, where the reflection may be more influenced by the incoherent scattering. Incidence angles larger than $50^{\circ}$ are discarded because they are out of the antenna beamwidth, and the main polarization is not guaranteed to be LHCP. This binning was previously used in [57] to analyze the correlation between GNSS-R data and optical, near-infrared and thermal indexes. To study the last point, a dedicated analysis for a grass-land region and a crops region is performed, as Figs. $4 \mathrm{a}-4 \mathrm{i}$ show a big region of the whole field campaign where different land cover and surface types were found. Figures $5 \mathrm{a}-$ $5 \mathrm{i}$ show the reflectivity, $\mathrm{T}_{B H}$, and $\mathrm{T}_{B V}$ for the three GELOz field campaigns over the grass-land focus area. Figures $6 a-6 \mathrm{i}$ shows the reflectivity, $\mathrm{T}_{B H}$, and $\mathrm{T}_{B V}$ for the three GELOz flights over the crops focus area. Again, qualitatively the same relationship than with the previous figure is obtained. Observations acquired with a roll or a pitch larger than $10^{\circ}$ were discarded, as well as data collected during the steep banking of the turns. Also if roll and pitch had changed more than $5^{\circ}$ per second, the data was also discarded as it would be an indication of a quick plane maneuver and antenna pattern compensation algorithms would not work properly.

1) Semi-arid grass-land: Figures 5a-5i show a summary of the grass-land dataset used for this analysis. A minimum distance algorithm has been used to associate each reflectivity point to each PLMR beam, guaranteeing that the distance is less than 100 meters according to the LARGO and PLMR ground-resolution for the three flights. If more than one PLMR $\mathrm{T}_{B}$ measurement fell within the same reflectivity point, they were averaged weighting them according to the inverse of their distance to the reflectivity point. Once the data were matched, the $I / 2$ parameter was computed and a correlation analysis between the reflectivity data and the $I / 2$ performed. Figure 7 shows this comparison for the different reflectivity incidence angle groups with Figs. 7(a)-(c) corresponding to the larger incidence angles group and Figs. 7(d)-(f) to the lower one, both compared to the data from the PLMR beams at their respective incidence angles from the bore sight. In red the 
best fit with the following shape is shown:

$$
I / 2=a\left(1-10^{\frac{R_{R L}[d B]}{10}}\right)
$$

where:

$$
I / 2=\frac{T_{B H}+T_{B V}}{2}=T_{F}\left(1-\frac{R_{H}+R_{V}}{2}\right),
$$

and:

$$
R_{R L} \approx \frac{R_{H}+R_{V}}{2},
$$

for the reflectivity incidence angle range used.

Table I shows the correlation of the data presented in Fig. 7 as well as the parameters of the proposed fit. The correlation among reflectivity and $I / 2$ for the PLMR beams $\pm 38^{\circ}$ and $\pm 21^{\circ}$ is 0.6 , while it decreases for the PLMR $\pm 8^{\circ}$ beams, probably due to surface roughness effects, since roughness affects more the forward scattering geometry at more nadir incidence angles. It is also noticeable that for the larger reflectivity incidence angles the Root Mean Square Error (RMSE) of the best fit is lower than for the lower incidence angles, which is also an indicator of the surface roughness effects. Finally, the $a$ parameter of the fit in all cases ranged from $270 \mathrm{~K}$ to $278 \mathrm{~K}$, and this parameter did not significantly change the goodness of the fit.

TABLE I: Correlation and RMSE between LARGO reflectivity and the first Stokes parameter divided by two for the grassland regions as well as the fit parameters.

\begin{tabular}{|c|c|c|c|c|}
\hline Param. & Inc. angle & $\pm 38.5^{\circ}$ & $\pm 21.5^{\circ}$ & $\pm 8^{\circ}$ \\
\hline \hline $\mathrm{a}[\mathrm{K}]$ & $30-50$ & 273.7 & 276.7 & 278.7 \\
\hline$R$ & $30-50$ & 0.6 & 0.61 & 0.51 \\
\hline RMSE [K] & $30-50$ & 6.6 & 7.1 & 8.9 \\
\hline \hline $\mathrm{a}[\mathrm{K}]$ & $0-30$ & 270 & 270 & 275 \\
\hline$R$ & $0-30$ & 0.6 & 0.58 & 0.41 \\
\hline RMSE [K] & $0-30$ & 9.2 & 9.8 & 10.2 \\
\hline
\end{tabular}

Despite the fit proposed was not highly sensitive to the $a$ parameter or the physical temperature of the terrain $\left(T_{F}\right)$, the reflectivity values were compared to the PI, which is a self-calibrated parameter independent from the physical temperature. This comparison follows the same structure than the one with the $I / 2$, and it is shown in Fig. 8 . The best fit proposed in this case is a potential one:

$$
T_{B}=a 10^{b R_{R L}[d B]}
$$

Table II shows the correlation between the reflectivity data and the PI computed from the PLMR $\mathrm{T}_{B} \mathrm{~S}$ as well as the best fit parameters. Correlation increased to approximately 0.65 due to using self-calibrated data. Furthermore, the same behavior than before is seen, the RMSE of the fits proposed is lower for the larger incidence angle reflectivity group, also indicating that surface roughness affects less the large incidence angles. However, the PI parameter only seems useful for the large PLMR incidence angles, as when the incidence angle is close to nadir, both $\mathrm{T}_{B H}$ and $\mathrm{T}_{B V}$ are practically equal, and the PI tends to 0 . The use of self-calibrated data allows the removal of any parameter affecting the relationship between reflectivity and brightness temperature and mitigates the surface roughness effects. However, the dependence of brightness temperature on the incidence angle plays a role, making the PI only useful for the large incidence angles regions. Conversely, the effect of the incidence angle was mitigated using the first Stokes parameter.

TABLE II: Correlation and RMSE between LARGO reflectivity and the PI for the grass-land regions as well as the fit parameters.

\begin{tabular}{|c|c|c|c|c|}
\hline Param. & Inc. angle & $\pm 38.5^{\circ}$ & $\pm 21.5^{\circ}$ & $\pm 8^{\circ}$ \\
\hline \hline $\mathrm{a}$ & $30-50$ & 0.26 & 0.1 & 0.03 \\
\hline $\mathrm{b}$ & $30-50$ & 0.03 & 0.04 & 0.06 \\
\hline$R$ & $30-50$ & 0.68 & 0.66 & 0.52 \\
\hline RMSE & $30-50$ & 0.02 & 0.008 & 0.003 \\
\hline \hline $\mathrm{a}$ & $0-30$ & 0.32 & 0.13 & 0.03 \\
\hline $\mathrm{b}$ & $0-30$ & 0.03 & 0.04 & 0.05 \\
\hline$R$ & $0-30$ & 0.66 & 0.63 & 0.31 \\
\hline RMSE & $0-30$ & 0.03 & 0.01 & 0.04 \\
\hline
\end{tabular}

2) Crops area: Figures 6a-6i show a summary of the crops data set used for this analysis. The dataset has been pre-processed in the same way as was pre-processed the grass-land dataset. The $I / 2$ parameter was computed and a correlation analysis between the reflectivity data and the $I / 2$ performed. Figure 9 shows this comparison for the two different reflectivity incidence angle groups. In red the best fit line is represented following the same linking model shown in Eqn. (14).

Table III shows the correlation of the data presented in Fig. 9 as well as the parameters of the proposed fit. The correlation among reflectivity and $I / 2$ for the three PLMR beams was between 0.74 and 0.8 for the reflectivity larger incidence angles, and between 0.64 and 0.69 for the lower incidence angles. For the crops area, the correlation increased in comparison to the grass-land area. This is an indication that the crops area, due to the agricultural works is a more regular region in terms of surface roughness than the grassland area. Analogously, the RMSE also increased slightly. The increase in the RMSE can be justified by the presence of higher vegetation, which adds some noise to the received signals. Also, the same behavior than before is accomplished, being the correlation smaller for the lower incidence angle group.

TABLE III: Correlation and RMSE between LARGO reflectivity and the first Stokes parameter divided by two for the crops region as well as the fit parameters.

\begin{tabular}{|c|c|c|c|c|}
\hline Param. & Inc. angle & $\pm 38.5^{\circ}$ & $\pm 21.5^{\circ}$ & $\pm 8^{\circ}$ \\
\hline \hline $\mathrm{a}[\mathrm{K}]$ & $30-50$ & 271.8 & 276.5 & 274.4 \\
\hline$R$ & $30-50$ & 0.8 & 0.74 & 0.78 \\
\hline RMSE [K] & $30-50$ & 8.7 & 9.8 & 11.4 \\
\hline \hline $\mathrm{a}[\mathrm{K}]$ & $0-30$ & 270 & 271.5 & 270 \\
\hline$R$ & $0-30$ & 0.69 & 0.66 & 0.64 \\
\hline RMSE [K] & $0-30$ & 11.3 & 11.4 & 15.4 \\
\hline
\end{tabular}


The same analysis than for the grass-land region with the PI parameter has been performed for the crops region and shown in Fig. 10. Also, the same fit as the one presented in Eqn. (17) is shown in red. Table IV shows the correlation between the reflectivity data and the PI computed from the PLMR $\mathrm{T}_{B} \mathrm{~S}$ as well as the best fit parameters. For the crops region the correlation values were similar to the grass-land region, increasing for the $\pm 38^{\circ}$ beam and large incidence angles. Again, no conclusion could be obtained for the $\pm 8^{\circ}$ beam, as it was always nearly 0 (by definition).

TABLE IV: Correlation and RMSE between LARGO reflectivity and the PI for the crops region as well as the fit parameters.

\begin{tabular}{|c|c|c|c|c|}
\hline Param. & Inc. angle & $\pm 38.5^{\circ}$ & $\pm 21.5^{\circ}$ & $\pm 8^{\circ}$ \\
\hline \hline $\mathrm{a}$ & $30-50$ & 0.33 & 0.1 & 0.06 \\
\hline $\mathrm{b}$ & $30-50$ & 0.04 & 0.03 & 0.07 \\
\hline$R$ & $30-50$ & 0.74 & 0.6 & 0.58 \\
\hline RMSE & $30-50$ & 0.035 & 0.022 & 0.007 \\
\hline \hline $\mathrm{a}$ & $0-30$ & 0.27 & 0.11 & 0.07 \\
\hline $\mathrm{b}$ & $0-30$ & 0.03 & 0.04 & 0.07 \\
\hline$R$ & $0-30$ & 0.66 & 0.51 & 0.45 \\
\hline RMSE & $0-30$ & 0.03 & 0.01 & 0.04 \\
\hline
\end{tabular}

\section{DISCUSSION}

There are several issues to take into account when analyzing the correlation between GNSS-R and microwave radiometry data, such as: incidence angle, surface roughness, land cover, polarization, and pixel size. Using the first Stokes parameter divided by two $(I / 2)$ it was possible to compensate for the polarization difference between PLMR $\mathrm{T}_{B} \mathrm{~s}$ and the LARGO reflectivity. If the land surface is smooth, the $I / 2$ curves are also flat, as the reflectivity, and the dependence on the incidence angle is also avoided. Using the PI it is possible to calibrate the data, whereas the dependence on the incidence angle is increased. Despite both areas analyzed being quite homogeneous, the two instruments were not looking to the same type of land surface cover due to differences in their pixel size. Moreover, the footprint size of the GNSS-R technique, and the sample interval is such that measurements taken every second are nearly independent, as there is only $10 \%$ overlapping among pixels. However, this is not the case with microwave radiometry data, since the pixel size is such that they are partially overlapped (50\%), and consequently correlated.

\section{A. Sensitivity to incidence angle and surface roughness}

It has been shown that independently from the land cover, the group of reflectivity values with incidence angles ranging from $30^{\circ}$ to $50^{\circ}$ has larger correlation with both the $I / 2$ and the PI than those below $30^{\circ}$. This indicates that mainly surface roughness, and with less importance vegetation structure and its water content, might have to be dealt with when trying to retrieve geophysical parameters such as soil moisture. For very large incidence angles (larger than $50^{\circ}$ ), the coherent component is the dominant component in the scattering process [30],
[58]-[60], unless the surface is very rough [61], where the coherent component finally disappears. For incidence angles from $30^{\circ}-50^{\circ}$, the coherent component dominates in most regions, except in some highly vegetated regions or with highly developed topography. For low incidence angles (lower than $30^{\circ}$ ) the surface roughness makes the coherent component decrease, and the incoherent component larger. Despite the coherent component is still measurable, its decrease is shown in the loss of correlation between the microwave radiometry and the GNSS-R data. Recent spaceborne data from the UK TDS-1 mission also supports that over land there is a coherent component present [55], [62], as the DDMs retrieved over land look like more to the Woodward Ambiguity Function (WAF) than to the sea surface (non-coherent) scattering model [34], [63], [64]. This is relevant because while the forthcoming GNSS-R satellite missions will have close to nadir-looking observations [65]-[67] mainly due to the antenna directivity requirements, results from field campaigns indicate that for GNSS-R scatterometry it may be useful to observe more slant angles, where the coherent scattering component becomes larger.

\section{B. Land cover effects}

In this work two different regions have been analyzed: a grass-land area, and a crops area. The crops area is normally a more regular area, and all fields have similar vegetation height and structure. Conversely, the grass-land is a low-vegetated area with different vegetation heights and some patches of bare soil. Surprisingly, whereas a crops area is vegetated and the grass-land area can vary its conditions, but it is normally low vegetated, the correlation between GNSS-R data is larger for the crops area than for the grass-land area. This occurs because unless the crops area has plants with very high vegetation water content, the L-band microwave GNSS waves pass trough vegetation and impinge on the ground beneath them. In those cases, the land surface is normally flatter and more regular than for the grass-land area, where there are more irregularities, or at least this was the case of the field campaign test sites. So, the reflection over the crops area is more coherent than over the grass-land area, and this is seen in a larger correlation between reflectivity, $(I / 2)$, and PI parameters for the crops area. Furthermore, it must be considered that the roughness affecting L-band is the large scale roughness, referring that also to the surface's slopes instead of only the surface RMSE.

\section{Sensitivity to pixel size}

The difference in the pixel size of the two instruments also plays a role in the data analysis performed. This effect is better seen in the two examples shown in Fig. 11. Therein, the reflectivity measurements from LARGO are plotted with small circles whereas the $\mathrm{T}_{B H}$ measurements from PLMR are written as colored text. Both measurements have been plotted over Google Earth. The color scale used for this plots is the same one used previously in Figs 4a-4i. Figure 11(a) shows how a water spot is detected as bright reflectivity points, whereas the water body is not present in the Google Earth Map. The $\mathrm{T}_{B H}$ for the left beam $\left( \pm 38^{\circ}\right)$ reduces its $\mathrm{T}_{B}$ 
measured, but it never reaches the water value $(\approx 100 \mathrm{~K})$ because of the beam filling factor. The water spot sensed by the GNSS-R instrument is at most $150 \mathrm{~m}$ size (2.5 times the reflectivity pixel size), whereas the microwave radiometer resolution for that beam is $153 \mathrm{~m} \times 73 \mathrm{~m}$ at $220 \mathrm{~m}$ height. So, due to the beam filling factor, the $\mathrm{T}_{B H}$ observed is a mixture of the one coming from the water spot and the surrounding land, and due to that it never reached the $\approx 100 \mathrm{~K}$. Note that in the same figure, the right $\mathrm{T}_{B H}$ PLMR beam also measures a descend in the $\mathrm{T}_{B}$, which occurs also due to the pixel size and the beam filling factor effect. It is also noticeable that PLMR data varies more smoothly whereas there is a sharp transition in the GNSS-R data. This shows some time correlation for the radiometer data which is not present on reflectivity data. This can also be understood as the difference in the pixel overlapping factor between the two techniques. Figure 11(b) shows a similar effect with a much smaller water area $(\sim$ $30 \mathrm{~m}$ x $30 \mathrm{~m}$ ) detected over Google Earth, which is clearly seen in the GNSS-R data while the radiometer data only decreases $10 \mathrm{~K}$. This effect is also related to the RMSE of the fits proposed, as the reflectivity data has stronger variations than the $\mathrm{T}_{B}$ data and adds some noise to the correlation curves, explaining the large RMSE observed.

Table V compares the different ground resolution (pixel size) for both instruments at different heights: $220 \mathrm{~m}$ and $1 \mathrm{~km}$, which would correspond to normal heights during airborne campaigns, and $630 \mathrm{~km}$ for spaceborne conditions (UK TDS1 mission parameters). The antenna beamwidth of the PLMR has been preserved for the data shown in that table in all conditions. For very low heights, such as $220 \mathrm{~m}$, the groundresolution of the reflectivity data is approximately half of the pixel size for the radiometry data in the along-track direction and one tenth in the across-track direction. For intermediate heights, such as $1 \mathrm{~km}$, the ground resolution of the reflectivity data is between $1 / 4$ and $1 / 5$ the pixel size of the radiometry data in the along-track direction and 1/20 in the across-track direction. For the spaceborne conditions the reflectivity data pixel size is much smaller than the radiometry data, specially for the across-track direction due to the integration time.

Also if a microwave radiometry spaceborne mission with different antenna parameters is considered, such as the SMOS mission (a ground spatial resolution of $40 \mathrm{~km} \mathrm{x} 40 \mathrm{~km}$ roughly), the reflectivity data pixel size is also much smaller than the radiometry data, leading to the concept of resolution enhancement, which would be of particular interest for spaceborne applications. Furthermore, differently from other synergy techniques [22]-[24], [57], in this case, both techniques work at very close frequency bands, which means that they are sensitive to the same geophysical parameters. This idea of down-scaling microwave radiometry data with GNSS-R data has been proposed recently by National Aeronautics and Space Administration (NASA), after the end of operations of SMAP radar [68].

\section{CONCLUSiOnS AND Future Lines}

This study has presented a qualitative and quantitative comparison between airborne GNSS-R data and L-band microwave radiometry, making use of the data of three different airborne field campaigns conducted over an experimental field site in South-Eastern Australia. In the field campaigns a GNSS-R scatterometer and the PLMR L-band microwave radiometer were flown together. In order to be able to compare the two datasets, linear polarization microwave radiometry data were converted to the first Stokes parameter divided by two $(I / 2)$. The PI was also computed from the brightness temperature measurements. Correlation results between both datasets for the three flights indicate that for large incidence angles $\left(>30^{\circ}\right)$ the coherent microwave radiometry model behaves quite well, as the surface seems to be smoother, in agreement with the Rayleigh criterion. Also, this indicates that the main dominating scattering mechanism for those incidence angles is the coherent one. For the crops region the correlation is between 0.74-0.8. For the grass-land region it is between $0.51-0.61$. For lower incidence angles in the reflectivity data $\left(<30^{\circ}\right)$, the correlation between reflectivity and $I / 2$ is smaller, ranging from $0.64-0.69$ for the crops region and roughly 0.6 for the grass-land region. In those cases, the surface appears rougher due to the scattering geometry, and the incoherent component starts to be noticeable. Furthermore, if the surface appears rougher, the received reflected power is smaller, and reflectivity measurements are more affected by noise, which is translated in larger RMSE for the proposed fits. The best correlation results were obtained when the coherent model works better (ie. larger incidence angles), and occurred for reflectivity incidence angles ranging from $30^{\circ}$ to $50^{\circ}$ and the $\pm 38^{\circ}$ beams for the crops region.

Furthermore, a discussion is performed justifying the differences between both datasets. It is mainly focused in three aspects: incidence angle and surface roughness, land cover, and pixel size. Regarding the pixel size, it is seen that due to the scattering properties of GNSS-R, measurements are nearly uncorrelated among them, and the spatial resolution is smaller than the radiometer data. This shows that GNSS-R data is able to detect features not seen in the $\mathrm{T}_{B} \mathrm{~S}$ measured, which means that both datasets can be used together to improve the spatial resolution of the brightness temperature data. Furthermore, correlation among both techniques indicate that they are sensitive to the same geophysical parameters.

\section{ACKNOWLEDGMENTS}

These activities have been sponsored by the Spanish Ministry of Science and Innovation, "AROSA-Advanced Radio Ocultations and Scatterometry Applications using GNSS and other opportunity signals", code AYA2011-29183-C0201/ESP, "AGORA: Técnicas Avanzadas en Teledetección Aplicada Usando Señales GNSS y Otras Señales de Oportunidad", code ESP2015-70014-C2-1-R (MINECO/FEDER), and a Monash University Faculty of Engineering 2013 Seed Grant. The authors acknowledge the support by ACROSS (Advanced Remote Sensing Ground-Truth Demo and Test Facilities) and TERENO (Terrestrial Environmental Observatories) funded by the German Helmholtz-Association. Special thanks go to Frank Winston and the participants in the field experiments for their support collecting in-situ data. Alberto 
TABLE V: Comparison of the ground resolution for both sensors at different flight heights and speeds. The two last columns refer to the instantaneous ground-resolution and to the integrated ground-resolution considering an integration time of $1 \mathrm{~s}$.

\begin{tabular}{|c|c|c|c|c|c|}
\hline Sensor & Inc. angle $[\mathrm{deg}]$ & Height $[\mathrm{m}]$ & Speed $[\mathrm{m} / \mathrm{s}]$ & Inst. Res. $[\mathrm{m} \times \mathrm{m}]$ & Integ. Res. [m x m] \\
\hline \hline LARGO & \pm 8 & 220 & 61.1 & $6.6 \times 6.6$ & $67.7 \times 6.6$ \\
\hline PLMR & \pm 8 & 220 & 61.1 & $58.2 \times 58.7$ & $119.3 \times 58.7$ \\
\hline LARGO & \pm 21 & 220 & 61.1 & $6.8 \times 7.2$ & $67.7 \times 7.2$ \\
\hline PLMR & \pm 21 & 220 & 61.1 & $61.7 \times 66.1$ & $122.8 \times 66.1$ \\
\hline LARGO & \pm 38 & 220 & 61.1 & $7.4 \times 9.3$ & $68.5 \times 9.3$ \\
\hline PLMR & \pm 38 & 220 & 61.1 & $73.1 \times 92.8$ & $134.2 \times 92.8$ \\
\hline \hline LARGO & \pm 8 & 1000 & 61.1 & $14.0 \times 14.1$ & $75.1 \times 14.1$ \\
\hline PLMR & \pm 8 & 1000 & 61.1 & $264.4 \times 267.0$ & $325.5 \times 267.0$ \\
\hline LARGO & \pm 21 & 1000 & 61.1 & $14.4 \times 15.4$ & $75.5 \times 15.4$ \\
\hline PLMR & \pm 21 & 1000 & 61.1 & $280.4 \times 300.4$ & $341.5 \times 300.4$ \\
\hline LARGO & \pm 38 & 1000 & 61.1 & $15.7 \times 19.9$ & $76.8 \times 19.9$ \\
\hline PLMR & \pm 38 & 1000 & 61.1 & $332.2 \times 421.6$ & $393.3 \times 421.6$ \\
\hline \hline LARGO & \pm 8 & 630000 & $6 \cdot 10^{3}$ & $351.3 \times 354.8$ & $6351.3 \times 354.8$ \\
\hline PLMR & \pm 8 & 630000 & $6 \cdot 10^{3}$ & $166554.5 \times 168191.3$ & $172554.5 \times 168191.3$ \\
\hline LARGO & \pm 21 & 630000 & $6 \cdot 10^{3}$ & $361.8 \times 387.6$ & $6361.8 \times 387.6$ \\
\hline PLMR & \pm 21 & 630000 & $6 \cdot 10^{3}$ & $176667.8 \times 189236.8$ & $182667.8 \times 189236.8$ \\
\hline LARGO & \pm 38 & 630000 & $6 \cdot 10^{3}$ & $393.8 \times 499.7$ & $6393.8 \times 499.7$ \\
\hline PLMR & \pm 38 & 630000 & $6 \cdot 10^{3}$ & $209303.7 \times 265610.3$ & $215303.8 \times 265610.3$ \\
\hline
\end{tabular}

Alonso Arroyo would like to thank also the financial support provided by the Fulbright commission in Spain through a Fulbright grant.

\section{REFERENCES}

[1] Y. Kerr, P. Waldteufel, J.-P. Wigneron, J. Martinuzzi, J. Font, and M. Berger, "Soil moisture retrieval from space: the Soil Moisture and Ocean Salinity (SMOS) mission," IEEE Transactions on Geoscience and Remote Sensing, vol. 39, no. 8, pp. 1729-1735, 2001. [Online]. Available: http://ieeexplore.ieee.org/lpdocs/epic03/wrapper.htm?arnumber=942551

[2] Y. H. Kerr, P. Waldteufel, J.-P. Wigneron, S. Delwart, F. Cabot, J. Boutin, M.-J. Escorihuela, J. Font, N. Reul, C. Gruhier, S. E. Juglea, M. R. Drinkwater, A. Hahne, M. Martin-Neira, and S. Mecklenburg, "The SMOS Mission: New Tool for Monitoring Key Elements ofthe Global Water Cycle," Proceedings of the IEEE, vol. 98, no. 5, pp. 666-687, May 2010. [Online]. Available: http://ieeexplore.ieee.org/lpdocs/epic03/wrapper.htm?arnumber=5446359

[3] D. Entekhabi, E. G. Njoku, P. E. O’Neill, K. H. Kellogg, W. T. Crow, W. N. Edelstein, J. K. Entin, S. D. Goodman, T. J. Jackson, J. Johnson, J. Kimball, J. R. Piepmeier, R. D. Koster, N. Martin, K. C. McDonald, M. Moghaddam, S. Moran, R. Reichle, J. C Shi, M. W. Spencer, S. W. Thurman, L. Tsang, and J. Van Zyl, "The Soil Moisture Active Passive (SMAP) Mission," Proceedings of the IEEE, vol. 98, no. 5, pp. 704-716, May 2010. [Online]. Available: http://ieeexplore.ieee.org/lpdocs/epic03/wrapper.htm?arnumber=5460980

[4] D. Long, P. Hardin, and P. Whiting, "Resolution enhancement of spaceborne scatterometer data," IEEE Transactions on Geoscience and Remote Sensing, vol. 31, no. 3, pp. 700-715, May 1993. [Online]. Available: http://ieeexplore.ieee.org/lpdocs/epic03/wrapper.htm?arnumber $=225536$

[5] R. Brown and R. Roeder, "Evolution of high spatial resolution spaceborne scatterometers," in Proceedings IEEE Southeastcon '98 'Engineering for a New Era'. IEEE, 1998, pp. 260-263. [Online]. Available: http://ieeexplore.ieee.org/lpdocs/epic03/wrapper.htm?arnumber=673344

[6] Z. Bartalis, W. Wagner, V. Naeimi, S. Hasenauer, K. Scipal, H. Bonekamp, J. Figa, and C. Anderson, "Initial soil moisture retrievals from the METOP-A Advanced Scatterometer (ASCAT)," Geophysical Research Letters, vol. 34, no. 20, p. L20401, Oct. 2007. [Online]. Available: http://doi.wiley.com/10.1029/2007GL031088
[7] L. Brocca, S. Hasenauer, T. Lacava, F. Melone, T. Moramarco, W. Wagner, W. Dorigo, P. Matgen, J. Martínez-Fernández, P. Llorens, J. Latron, C. Martin, and M. Bittelli, "Soil moisture estimation through ASCAT and AMSR-E sensors: An intercomparison and validation study across Europe," Remote Sensing of Environment, vol. 115, no. 12, pp. 3390-3408, Dec. 2011. [Online]. Available: http://linkinghub.elsevier.com/retrieve/pii/S0034425711002756

[8] A. Bentamy, D. Croize-Fillon, and C. Perigaud, "Characterization of ASCAT measurements based on buoy and QuikSCAT wind vector observations," Ocean Science, vol. 4, no. 4, pp. 265-274, Dec. 2008. [Online]. Available: http://www.ocean-sci.net/4/265/2008/

[9] Xiaofeng Yang, Xiaofeng Li, W. G. Pichel, and Ziwei $\mathrm{Li}$, "Comparison of Ocean Surface Winds From ENVISAT ASAR, MetOp ASCAT Scatterometer, Buoy Measurements, and NOGAPS Model," IEEE Transactions on Geoscience and Remote Sensing, vol. 49, no. 12, pp. 4743-4750, Dec. 2011. [Online]. Available: http://ieeexplore.iee.org/lpdocs/epic03/wrapper.htm?arnumber=5966334

[10] C. Hall and R. Cordey, "Multistatic Scatterometry," in International Geoscience and Remote Sensing Symposium, 'Remote Sensing: Moving Toward the 21st Century'. IEEE, 1988, pp. 561-562. [Online]. Available: http://ieeexplore.ieee.org/lpdocs/epic03/wrapper.htm?arnumber $=570200$

[11] D. Masters, P. Axelrad, and S. Katzberg, "Initial results of land-reflected GPS bistatic radar measurements in SMEX02," Remote Sensing of Environment, vol. 92, no. 4, pp. 507-520, Sep. 2004. [Online]. Available: http://linkinghub.elsevier.com/retrieve/pii/S0034425704001828

[12] A. Moccia and A. Renga, "Spatial Resolution of Bistatic Synthetic Aperture Radar: Impact of Acquisition Geometry on Imaging Performance," IEEE Transactions on Geoscience and Remote Sensing, vol. 49, no. 10, pp. 3487-3503, Oct. 2011. [Online]. Available: http://ieeexplore.ieee.org/lpdocs/epic03/wrapper.htm?arnumber=5729807

[13] E. Valencia, A. Camps, N. Rodriguez-Alvarez, H. Park, and I. Ramos-Perez, "Using GNSS-R Imaging of the Ocean Surface for Oil Slick Detection," IEEE Journal of Selected Topics in Applied Earth Observations and Remote Sensing, vol. 6, no. 1, pp. 217-223, Feb. 2013. [Online]. Available: http://ieeexplore.ieee.org/lpdocs/epic03/wrapper.htm?arnumber=6293919

[14] A. Egido, S. Paloscia, E. Motte, L. Guerriero, N. Pierdicca, M. Caparrini, E. Santi, G. Fontanelli, and N. Floury, "Airborne GNSS-R Polarimetric Measurements for Soil Moisture and Above-Ground Biomass Estimation," IEEE Journal of Selected Topics in Applied Earth Observations and Remote Sensing, vol. 7, no. 5, pp. 1522-1532, May 2014. [Online]. Available: http://ieeexplore.ieee.org/xpls/abs_all.jsp?arnumber $=6822537 \& t a g=1$ 
http://ieeexplore.ieee.org/lpdocs/epic03/wrapper.htm?arnumber=6822537

[15] S. J. Katzberg, O. Torres, M. S. Grant, and D. Masters, "Utilizing calibrated GPS reflected signals to estimate soil reflectivity and dielectric constant: Results from SMEX02," Remote Sensing of Environment, vol. 100, no. 1, pp. 17-28, Jan. 2006. [Online]. Available: http://linkinghub.elsevier.com/retrieve/pii/S0034425705002932

[16] G. Foti, C. Gommenginger, P. Jales, M. Unwin, A. Shaw, C. Robertson, and J. Roselló, "Spaceborne GNSS reflectometry for ocean winds: First results from the UK TechDemoSat-1 mission," Geophysical Research Letters, vol. 42, no. 13, pp. 5435-5441, Jul. 2015. [Online]. Available: http://doi.wiley.com/10.1002/2015GL064204

[17] V. Zavorotny, A. Gasiewski, R. Zamora, E. McIntyre, V. Leuski, and V. Irisov, "Stationary L-Band Radiometry for Seasonal Measurements of Soil Moisture," in 2006 IEEE International Symposium on Geoscience and Remote Sensing. IEEE, Jul. 2006, pp. 2028-2031. [Online]. Available: http://ieeexplore.ieee.org/lpdocs/epic03/wrapper.htm?arnumber=4241672

[18] C. Rudiger, M. Doubkova, J. R. Larsen, W. Wagner, and J. P. Walker, "Similarities Between Spaceborne Active and Airborne Passive Microwave Observations at $1 \mathrm{~km}$ Resolution," IEEE Geoscience and Remote Sensing Letters, vol. 11, no. 12, pp. 2178-2182, Dec. 2014. [Online]. Available: http://ieeexplore.ieee.org/lpdocs/epic03/wrapper.htm?arnumber=6827203

[19] M. Piles, A. Camps, M. Vall-llossera, and M. Talone, "SpatialResolution Enhancement of SMOS Data: A Deconvolution-Based Approach," IEEE Transactions on Geoscience and Remote Sensing, vol. 47, no. 7, pp. 2182-2192, Jul. 2009. [Online]. Available: http://ieeexplore.ieee.org/lpdocs/epic03/wrapper.htm?arnumber=4806104

[20] F. Lenti, F. Nunziata, C. Estatico, and M. Migliaccio, "On the Spatial Resolution Enhancement of Microwave Radiometer Data in Banach Spaces," IEEE Transactions on Geoscience and Remote Sensing, vol. 52, no. 3, pp. 1834-1842, Mar. 2014. [Online]. Available: http://ieeexplore.ieee.org/lpdocs/epic03/wrapper.htm?arnumber=6517236

[21] F. Lenti, F. Nunziata, C. Estatico, and M. Migliaccio, "Conjugate Gradient Method in Hilbert and Banach Spaces to Enhance the Spatial Resolution of Radiometer Data," IEEE Transactions on Geoscience and Remote Sensing, vol. 54, no. 1, pp. 397-406, Jan. 2016. [Online]. Available: http://ieeexplore.ieee.org/lpdocs/epic03/wrapper.htm?arnumber=7243319

[22] O. Merlin, A. Chehbouni, J. Walker, R. Panciera, and Y. Kerr, "A Simple Method to Disaggregate Passive Microwave-Based Soil Moisture," IEEE Transactions on Geoscience and Remote Sensing, vol. 46, no. 3, pp. 786-796, Mar. 2008. [Online]. Available: http://ieeexplore.ieee.org/lpdocs/epic03/wrapper.htm?arnumber=4448971

[23] O. Merlin, J. Walker, A. Chehbouni, and Y. Kerr, "Towards deterministic downscaling of SMOS soil moisture using MODIS derived soil evaporative efficiency," Remote Sensing of Environment, vol. 112, no. 10, pp. 3935-3946, Oct. 2008. [Online]. Available: http://linkinghub.elsevier.com/retrieve/pii/S0034425708002204

[24] M. Piles, A. Camps, M. Vall-1lossera, I. Corbella, R. Panciera, C. Rudiger, Y. H. Kerr, and J. Walker, "Downscaling SMOS-Derived Soil Moisture Using MODIS Visible/Infrared Data," IEEE Transactions on Geoscience and Remote Sensing, vol. 49, no. 9, pp. 3156-3166, Sep. 2011. [Online]. Available: http://ieeexplore.ieee.org/lpdocs/epic03/wrapper.htm?arnumber=5756664

[25] M. Martín-Neira, "A passive reflectometry and interferometry system(PARIS): Application to ocean altimetry," ESA Journal, vol. 17, pp. 331-355, 1993. [Online]. Available: http://xenon.colorado.edu/spotlight/kb/gps_reflections/MartinNeira-PARIS-1993.pdf

[26] J.-C. Auber, A. Bibaut, and J.-M. Rigal, "Characterization of Multipath on Land and Sea at GPS Frequencies," in Proceedings of the 7th International Technical Meeting of the Satellite Division of The Institute of Navigation (ION GPS 1994), Salt Lake City, 1994, pp. 1155-1171. [Online]. Available: http://iop.science.ion.org/publications/abstract.cfm?articleID $=4024$

[27] V. Zavorotny and A. Voronovich, "Bistatic GPS signal reflections at various polarizations from rough land surface with moisture content," in IGARSS 2000. IEEE 2000 International Geoscience and Remote Sensing Symposium. Taking the Pulse of the Planet: The Role of Remote Sensing in Managing the Environment. Proceedings (Cat. No.00CH37120), vol. 7, no. 303. IEEE, 2000, pp. 2852-2854. [Online]. Available: http://ieeexplore.ieee.org/lpdocs/epic03/wrapper.htm?arnumber=860269

[28] D. Masters, "Surface Remote Sensing Applications of GNSS Bistatic Radar: Soil Moisture and Aircraft Altimetry," Ph.D. dissertation, University of Colorado, 2004.
[29] A. Egido, M. Caparrini, G. Ruffini, S. Paloscia, E. Santi, L. Guerriero, N. Pierdicca, and N. Floury, "Global Navigation Satellite Systems Reflectometry as a Remote Sensing Tool for Agriculture," Remote Sensing, vol. 4, no. 12, pp. 2356-2372, Aug. 2012. [Online]. Available: http://www.mdpi.com/2072-4292/4/8/2356/

[30] A. Alonso-Arroyo, A. Camps, A. Monerris, C. Rüdiger, J. P. Walker, G. Forte, D. Pascual, H. Park, and R. Onrubia, "The light airborne reflectometer for GNSS-R observations (LARGO) instrument: Initial results from airborne and Rover field campaigns," in 2014 IEEE Geoscience and Remote Sensing Symposium. IEEE, Jul. 2014, pp. 4054-4057. [Online]. Available: http://ieeexplore.ieee.org/lpdocs/epic03/wrapper.htm?arnumber=6947376

[31] R. De Roo and F. Ulaby, "Bistatic specular scattering from rough dielectric surfaces," IEEE Transactions on Antennas and Propagation, vol. 42, no. 2, pp. 220-231, 1994. [Online]. Available: http://ieeexplore.ieee.org/lpdocs/epic03/wrapper.htm?arnumber=277216

[32] G. Lerondel and R. Romestain, "Fresnel coefficients of a rough interface," Applied Physics Letters, vol. 74, no. 19, p. 2740, 1999. [Online]. Available: http://link.aip.org/link/APPLAB/v74/i19/p2740/s1\&Agg=doi

[33] P. Beckmann and A. Spizzichino, The Scattering of Electromagnetic Waves From Rough Surfaces, artech hou ed. Artech Print on Demand, 1987.

[34] V. Zavorotny and A. Voronovich, "Scattering of GPS signals from the ocean with wind remote sensing application," IEEE Transactions on Geoscience and Remote Sensing, vol. 38, no. 2, pp. 951-964, Mar. 2000. [Online]. Available: http://ieeexplore.ieee.org/lpdocs/epic03/wrapper.htm?arnumber=841977

[35] T. Schmugge, P. Gloersen, T. Wilheit, and F. Geiger, "Remote sensing of soil moisture with microwave radiometers," Journal of Geophysical Research, vol. 79, no. 2, pp. 317-323, Jan. 1974. [Online]. Available: http://doi.wiley.com/10.1029/JB079i002p00317

[36] T. J. Schmugge, W. P. Kustas, J. C. Ritichie, T. J. Jackson, and A. Rango, "Remote sensing in hydrology," Advances in Water Resources, vol. 25, pp. 1367-1385, 2002. [Online]. Available: http://nora.nerc.ac.uk/5817/

[37] A. K. Fung, Microwave Scattering and Emission Models and their Applications. Artech House Publishers, 1994.

[38] J. R. Wang and T. J. Schmugge, "An Empirical Model for the Complex Dielectric Permittivity of Soils as a Function of Water Content," IEEE Transactions on Geoscience and Remote Sensing, vol. GE-18, no. 4, pp. 288-295, Oct. 1980. [Online]. Available: http://ieeexplore.ieee.org/lpdocs/epic03/wrapper.htm?arnumber=4157179

[39] M. Hallikainen, F. Ulaby, M. Dobson, M. El-rayes, and L.-k. Wu, "Microwave Dielectric Behavior of Wet SoilPart 1: Empirical Models and Experimental Observations," IEEE Transactions on Geoscience and Remote Sensing, vol. GE-23, no. 1, pp. 25-34, Jan. 1985. [Online]. Available: http://ieeexplore.ieee.org/lpdocs/epic03/wrapper.htm?arnumber=4072239

[40] M. Dobson, F. Ulaby, M. Hallikainen, and M. El-rayes, "Microwave Dielectric Behavior of Wet Soil-Part II: Dielectric Mixing Models," IEEE Transactions on Geoscience and Remote Sensing, vol. GE-23, no. 1, pp. 35-46, Jan. 1985. [Online]. Available: http://ieeexplore.ieee.org/lpdocs/epic03/wrapper.htm?arnumber=4072240

[41] V. Mironov, M. Dobson, V. Kaupp, S. Komarov, and V. Kleshchenko, "Generalized refractive mixing dielectric model for moist soils," IEEE Transactions on Geoscience and Remote Sensing, vol. 42, no. 4, pp. 773-785, Apr. 2004. [Online]. Available: http://ieeexplore.ieee.org/lpdocs/epic03/wrapper.htm?arnumber=1288372

[42] A. Alonso-Arroyo, A. Camps, A. Aguasca, G. Forte, A. Monerris, C. Rüdiger, J. P. Walker, H. Park, D. Pascual, and R. Onrubia, "Improving the Accuracy of Soil Moisture Retrievals Using the Phase Difference of the Dual-Polarization GNSS-R Interference Patterns," IEEE Geoscience and Remote Sensing Letters, vol. 11, no. 12, pp. 2090-2094, Dec. 2014. [Online]. Available: http://ieeexplore.ieee.org/lpdocs/epic03/wrapper.htm?arnumber=6814795

[43] W. H. McMaster, "Polarization and the Stokes Parameters," American Journal of Physics, vol. 22, no. 6, p. 351, 1954. [Online]. Available: http://scitation.aip.org/content/aapt/journal/ajp/22/6/10.1119/1.1933744

[44] W. H. McMaster, "Matrix Representation of Polarization," Reviews of Modern Physics, vol. 33, no. 1, pp. 8-28, Jan. 1961. [Online]. Available: http://link.aps.org/doi/10.1103/RevModPhys.33.8

[45] J. P. Randa, J. Lahtinen, A. Camps, A. Gasiewski, M. Hallikainen, D. Leine V, M. Martin-Neira, J. Piepmeier, P. Rosenkranz, C. Ruf, J. Shiue, and N. Skou, "Recommended Terminology For Microwave Radiometry," National Institute of Standards and Technology (NIST), Boulder, Tech. Rep., 2008. [Online]. Available: http://www.nist.gov/customcf/get_pdf.cfm?pub_id=33079 
[46] S. Paloscia and P. Pampaloni, "Microwave polarization index for monitoring vegetation growth," IEEE Transactions on Geoscience and Remote Sensing, vol. 26, no. 5, pp. 617-621, 1988. [Online]. Available: http://ieeexplore.ieee.org/lpdocs/epic03/wrapper.htm?arnumber=7687

[47] J.-P. Wigneron, J.-C. Calvet, T. Pellarin, A. Van de Griend, M. Berger, and P. Ferrazzoli, "Retrieving near-surface soil moisture from microwave radiometric observations: current status and future plans," Remote Sensing of Environment, vol. 85, no. 4, pp. 489-506, Jun. 2003. [Online]. Available: http://linkinghub.elsevier.com/retrieve/pii/S0034425703000518

[48] R. Panciera, J. Walker, J. Kalma, E. Kim, J. Hacker, O. Merlin, M. Berger, and N. Skou, "The NAFE'05/CoSMOS Data Set Toward SMOS Soil Moisture Retrieval, Downscaling, and Assimilation," IEEE Transactions on Geoscience and Remote Sensing, vol. 46, no. 3, pp. 736-745, Mar. 2008. [Online]. Available: http://ieeexplore.ieee.org/lpdocs/epic03/wrapper.htm?arnumber=444672.

[49] Oxford Technical Solutions Ltd, “OxTS RT3003," 2016. [Online]. Available: http://www.oxts.com/products/rt3000-family/

[50] A. B. Smith, J. P. Walker, A. W. Western, R. I. Young, K. M. Ellett, R. C. Pipunic, R. B. Grayson, L. Siriwardena, F. H. S. Chiew, and H. Richter, "The Murrumbidgee soil moisture monitoring network data set," Water Resources Research, vol. 48, no. 7, pp. n/a-n/a, Jul. 2012 [Online]. Available: http://doi.wiley.com/10.1029/2012WR011976

[51] "Polarimetric L-Band Microwave Radiometer (PLMR)," 2015. [Online]. Available: http://www.prosensing.com/sensors/radiometers/soilmoisture/plmr/

[52] M. Unwin, S. Gleason, and M. Brennan, "The Space GPS Reflectometry Experiment on the UK Disaster Monitoring Constellation Satellite," in Proceedings of the 16th International Technical Meeting of the Satellite Division of The Institute of Navigation (ION GPS/GNSS 2003), 2003, p. 2656. [Online]. Available: https://www.ion.org/publications/abstract.cfm?articleID=5453

[53] S. Gleason, S. Hodgart, Yiping Sun, C. Gommenginger, S. Mackin, M. Adjrad, and M. Unwin, "Detection and Processing of bistatically reflected GPS signals from low Earth orbit for the purpose of ocean remote sensing," IEEE Transactions on Geoscience and Remote Sensing, vol. 43, no. 6, pp. 1229-1241, Jun. 2005. [Online]. Available: http://ieeexplore.ieee.org/lpdocs/epic03/wrapper.htm?arnumber=1433022

[54] S. Gleason, "Remote Sensing of Ocean, Ice and Land Surfaces Using Bistatically Scattered GNSS Signals From Low Earth Orbit," Ph.D. dissertation, University of Surrey, 2006.

[55] M. Unwin, "The SGR-ReSI Experiment on the TechDemoSat-1 Mission," in TechDemoSat-1 User Consultation Workshop, 2015. [Online]. Available: http://www.merrbys.co.uk:8080/CatalogueData/Documents/TDS-1 SGR-ReSI Experiment.pdf

[56] S. Gleason, GNSS Applications and Methods, first edit ed., S. Gleason and D. Gebre-Egziabher, Eds. Artech House Publishers, 2009.

[57] N. Sánchez, A. Alonso-Arroyo, J. Martínez-Fernández, M. Piles, A. González-Zamora, A. Camps, and M. Vall-llosera, "On the Synergy of Airborne GNSS-R and Landsat 8 for Soil Moisture Estimation," Remote Sensing, vol. 7, no. 8, pp. 9954-9974, Aug. 2015. [Online]. Available: http://www.mdpi.com/2072-4292/7/8/9954/

[58] V. U. Zavorotny, K. M. Larson, J. J. Braun, E. E. Small, E. D. Gutmann, and A. L. Bilich, "A Physical Model for GPS Multipath Caused by Land Reflections: Toward Bare Soil Moisture Retrievals," IEEE Journal of Selected Topics in Applied Earth Observations and Remote Sensing, vol. 3, no. 1, pp. 100-110, Mar. 2010. [Online]. Available: http://ieeexplore.ieee.org/lpdocs/epic03/wrapper.htm?arnumber=5290072 http://ieeexplore.ieee.org/lpdocs/epic03/wrapper.htm?arnumber $=5325890$

[59] N. Rodriguez-Alvarez, A. Camps, M. Vall-llossera, X. Bosch-Lluis, A. Monerris, I. Ramos-Perez, E. Valencia, J. F. MarchanHernandez, J. Martinez-Fernandez, G. Baroncini-Turricchia, C. Perez-Gutierrez, and N. Sanchez, "Land Geophysical Parameters Retrieval Using the Interference Pattern GNSS-R Technique," IEEE Transactions on Geoscience and Remote Sensing, vol. 49, no. 1, pp. 71-84, Jan. 2011. [Online]. Available: http://ieeexplore.ieee.org/lpdocs/epic03/wrapper.htm?arnumber=5475216

[60] K. M. Larson, J. J. Braun, E. E. Small, V. U. Zavorotny, E. D. Gutmann, and A. L. Bilich, "GPS Multipath and Its Relation to Near-Surface Soil Moisture Content," IEEE Journal of Selected Topics in Applied Earth Observations and Remote Sensing, vol. 3, no. 1, pp. 91-99, Mar. 2010. [Online]. Available: http://ieeexplore.ieee.org/lpdocs/epic03/wrapper.htm?arnumber $=5325890$

[61] A. Alonso-Arroyo, A. Camps, H. Park, D. Pascual, R. Onrubia, and F. Martin, "Retrieval of Significant Wave Height and Mean Sea Surface Level Using the GNSS-R Interference Pattern
Technique: Results From a Three-Month Field Campaign,' IEEE Transactions on Geoscience and Remote Sensing, vol. 53, no. 6, pp. 3198-3209, Jun. 2015. [Online]. Available: http://ieeexplore.ieee.org/lpdocs/epic03/wrapper.htm?arnumber=6990586

[62] "UK Tech-DemoSAT." [Online]. Available: http://www.sstl.co.uk/Missions/TechDemoSat-1-Launched-2014

[63] "UK Tech-DemoSAT data." [Online]. Available: http://www.merrbys.co.uk/

[64] V. U. Zavorotny, S. Gleason, E. Cardellach, and A. Camps, "Tutorial on Remote Sensing Using GNSS Bistatic Radar of Opportunity," IEEE Geoscience and Remote Sensing Magazine, vol. 2, no. 4, pp. 8-45, 2014. [Online]. Available: http://ieeexplore.ieee.org/lpdocs/epic03/wrapper.htm?arnumber=6985926

[65] "Cyclone Global Navigation Satellite System (CYGNSS)." [Online]. Available: http://aoss-research.engin.umich.edu/missions/cygnss/

[66] "Cyclone Global Navigation Satellite System (CYGNSS)." [Online]. Available: http://science.nasa.gov/missions/cygnss/

[67] A. Camps, H. Park, A. Ghavidel, J. M. Rius, and I. Sekulic, "GEROS-ISS, a demonstration mission of GNSS remote sensing capabilities to derive geophysical parameters of the earth surfaces: Altimetry performance evaluation," in 2015 IEEE International Geoscience and Remote Sensing Symposium (IGARSS). IEEE, Jul. 2015, pp. 3917-3920. [Online]. Available: http://ieeexplore.ieee.org/lpdocs/epic03/wrapper.htm?arnumber=7326681

[68] S. T. Lowe, S. Chan, S. Esterhuizen, A. Freedman, S. Oveisgharan, and L. Young, "GNSS-Reflectometry with NASA's Soil Moisture Active/Passive Mission," in USNC-URSI National Radio Science Meeting, Boulder, 2016

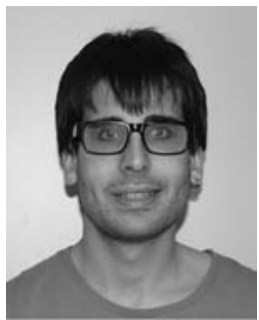

Alberto Alonso Arroyo (S'11) was born in Barcelona, Spain. He received the M.S. degree in telecommunications engineering in $2011(\mathrm{BSc}+5)$ and the M.S. in Research on Information and Communication Technologies in 2012 (MSc+2) both from the Universitat Politècnica de CatalunyaBarcelonaTech. He is working towards the $\mathrm{Ph} . \mathrm{D}$. degree in GNSS-Reflectometry, with the Passive Remote Sensing Group, Department of Signal Theory and Communications, at the Universitat Politècnica de Catalunya-BarcelonaTech. He has been during one year at the NOAA/ERSL research center in Boulder as a part of his $\mathrm{PhD}$ program thanks to a Fulbright grant.

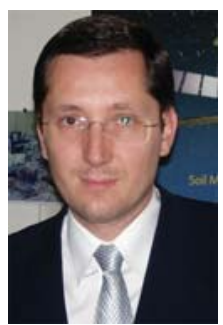

Adriano Camps (S'91-A'97-M'00-SM'03-F'11) was born in Barcelona, Spain, in 1969. He received the degree in telecommunications engineering and $\mathrm{Ph} . \mathrm{D}$. degree in telecommunications engineering from the Universitat Politècnica de Catalunya (UPC), Barcelona, Spain, in 1992 and 1996, respectively. In 1991 to 1992 , he was at the ENS des Télécommunications de Bretagne, France, with an Erasmus Fellowship. Since 1993, he has been with the Electromagnetics and Photonics Engineering Group, Department of Signal Theory and Communications, UPC, where he was first Assistant Professor, Associate Professor in 1997, and Full Professor since 2007. In 1999, he was on sabbatical leave at the Microwave Remote Sensing Laboratory, of the University of Massachusetts, Amherst. Since 1993, he has been deeply involved in the European Space Agency SMOS Earth Explorer Mission, and since 2001 on the use of GNSS-R techniques to perform the sea state correction needed to retrieve salinity from radiometric observations. He has received a number of awards for his research and teaching activies, among which the Research Distinction of the Generalitat de Catalunya (2002) for contributions to microwave passive remote sensing; the European Young Investigator Award (2004) of the European Science Foundation, the ICREA Academia award (2009), and the 1st (2000) and 7th (2010) Duran Farell Awards. He has published more than 125 peer-reviewed journal papers, and more than 250 international conference presentations. 


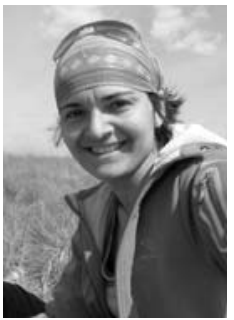

Alessandra Monerris received the B.E. degree in electrical engineering from the Universitat Politècnica de València, and the Ph.D. degree in remote sensing from the Universitat Politècnica de Catalunya, Spain. From 2007 to 2011, she was the executive director at the Soil Moisture and Ocean Salinity Expert Centre in Barcelona (SMOS-BEC). Then, she joined the Department of Civil Engineering from Monash University, Australia, as a research fellow. She has extensive experience in the preparation and coordination of field experiments for the validation of soil moisture products derived from proximal and remote sensing data. She has been responsible for the Australian OzNet soil moisture monitoring network, and the Yanco CosmOz tower management. Her research interests include soil moisture and crop properties estimation from passive microwave observations, cosmic-ray probes, and Global Navigation Satellite Systems Reflectometry (GNSS-R)

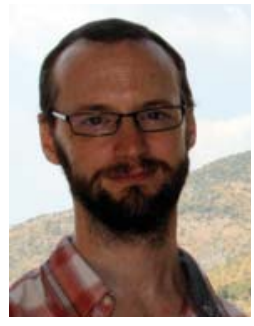

Cristoph Rüdiger (M'10-SM'15) received the B.E. degree in civil engineering in 2002 from the University of Applied Sciences of Wiesbaden (now RheinMain University of Applied Sciences), Germany, and the Ph.D. degree in environmental engineering in 2007 from the University of Melbourne, Melbourne, Australia. Since 2011, he has been a Senior Lecturer with the Department of Civil Engineering, at Monash University, Australia

In 2006, he joined the Centre National de Recherches Météorologiques (CNRM) at Météo France, Toulouse, France, to work on the preparation of surface soil moisture and LAI data assimilation into the French land surface model ISBA. In 2007 he was awarded a Centre National d'Etudes Spatiales (CNES) post-doctoral fellowship on the same topic, and to assess the accuracy of current remotely sensed soil moisture products. Since his return to Australia in July 2008, he has coordinated and led a number of cal/val campaigns for the Australian land validation segment of the SMOS and SMAP missions in the Australian arid zone and the Murrumbidgee River catchment. In addition, he is a PI on JAXA's GCOM-C and GCOM-W missions. In 2012, he was received an Australian Academy of Sciences Early Career Travel Fellowship for his work on remote sensing. His research interests include remote sensing of vegetation dynamics and landscape water content for the prediction of bushfire risks, as well as ecosystem adaptation to climate change.

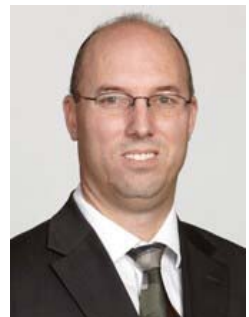

Professor Jeffrey Walker received his B.E. (Civil) and B.Surveying degrees in 1995 with Hons 1 an University Medal from the University of Newcastle, Australia, and his Ph.D. in Water Resources Engineering from the same University in 1999. His $\mathrm{Ph} . \mathrm{D}$. thesis was among the early pioneering research on estimation of root-zone soil moisture from assimilation of remotely sensed surface soil moisture observations. He then joined NASA Goddard Space Flight Centre to implement his soil moisture work globally. In 2001 he moved to the Department of Civil and Environmental Engineering at the University of Melbourne as Lecturer, where he continued his soil moisture work, including development of the only Australian airborne capability for simulating new satellite missions for soil moisture. In 2010 he was appointed as Professor in the Department of Civil Engineering at Monash University where he is continuing this research. $\mathrm{He}$ is contributing to soil moisture satellite missions at NASA, ESA and JAXA, as a Science Team member for the Soil Moisture Active Passive (SMAP) mission and Cal/val Team member for the Soil Moisture and Ocean Salinity (SMOS) and Global Change Observation Mission - Water (GCOMW) respectively.

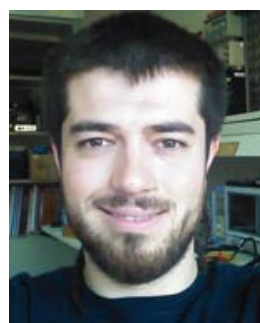

Raul Onrubia ( $\left.\mathrm{S}^{\prime} 10\right)$ was born in Barcelona, Spain. He received the B.Sc. degree $(\mathrm{BSc}+5)$ in telecommunications engineering the M.Sc. degree $(\mathrm{Msc}+2)$ in research on information and communication technologies from the Universitat Politécnica de Catalunya, Barcelona, Spain in 2012 and 2014, respectively. He is currently working toward the $\mathrm{PhD}$. degree in GNSS-Reflectometry with the Passive Remote Sensing Group, Signal Theory and Communications Department, Universitat Politècnica de Catalunya-BarcelonaTech, Barcelona, Spain. His current work is the development of RF hardware, and the study of interferences and mitigation techniques.

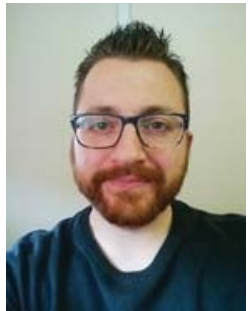

Jorge Querol (S'13) was born in Castelló, Spain, in 1987. He received the M.Sc. degree in electronics engineering, M.Sc. degree in telecommunication engineering and M.Sc. degree in photonics from the UPC-BarcelonaTech in 2011, 2012 and 2013, respectively. Currently, he is a Ph.D. candidate working as graduate research assistant at the Remote Sensing Laboratory (RSLab) at UPCBarcelonaTech, Barcelona, Spain. His research deals with the development of real-time signal processing systems able to detect and mitigate the effects of Radio-Frequency Interference (RFI) signals and jamming in Global Navigation Satellite Systems (GNSS) and Passive Remote Sensing (PRS) applications, particularly, those ones working in L-band such as MicroWave (MW) radiometry and GNSS-Reflectometry (GNSS-R).

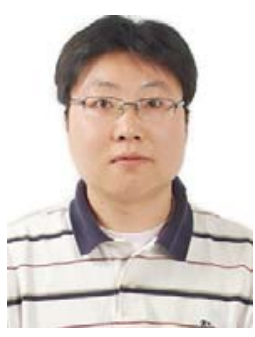

Hyuk Park (S'05-AM'09-M'12-SM'15) was born in South Korea. He received the B.S. degree in mechanical engineering from the Korea Advanced Institute of Science and Technology, Daejeon, Korea, in 2001 and the M.S. and Ph.D. degrees in information and mechatronics from Gwangju Institute of Science and Technology, Gwangju, Korea, in 2003 and 2009 , respectively. In 2009, he joined the Remote Sensing Group, Polytechnic University of Catalonia (UPC), Barcelona, Spain, as a Postdoctoral Researcher. In 2011, he was a grant holder of National Research Foundation funded by the Korean Government. Since 2012, he has been working as a Research Associate with a Juan de la Cierva grant funded by the Spanish Ministry of Economy and Competitiveness. He is currently with the Passive Remote Sensing Group, UPC, for satellite remote sensing for microwave radiometry and Global Navigation Satellite Systems reflectometry. His main research interest is in the area of remote sensing, particularly passive microwave remote sensing, including system design, modeling and simulation, and image processing

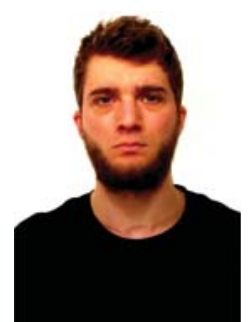

Daniel Pascual (S'11) was born in Barcelona, Spain, in 1985 . He received the $\mathrm{BSc}+5$ degree in telecommunications engineering specialized in communications in 2011, and the MSc+2 degree in Research on Information and Communication Technologies in 2014, both from the Universitat Politècnica de Catalunya (UPC), Barcelona, Spain. In 2011 he joined the Passive Remote Sensing Group from UPC where he is currently working toward the PhD degree in GNSS-Reflectometry focused in ocean altimetry. 


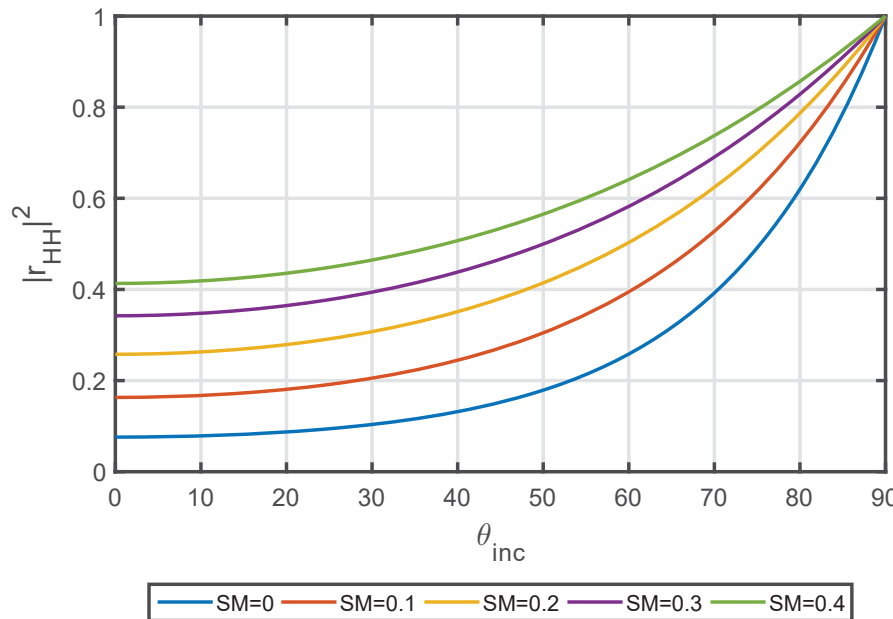

(a)

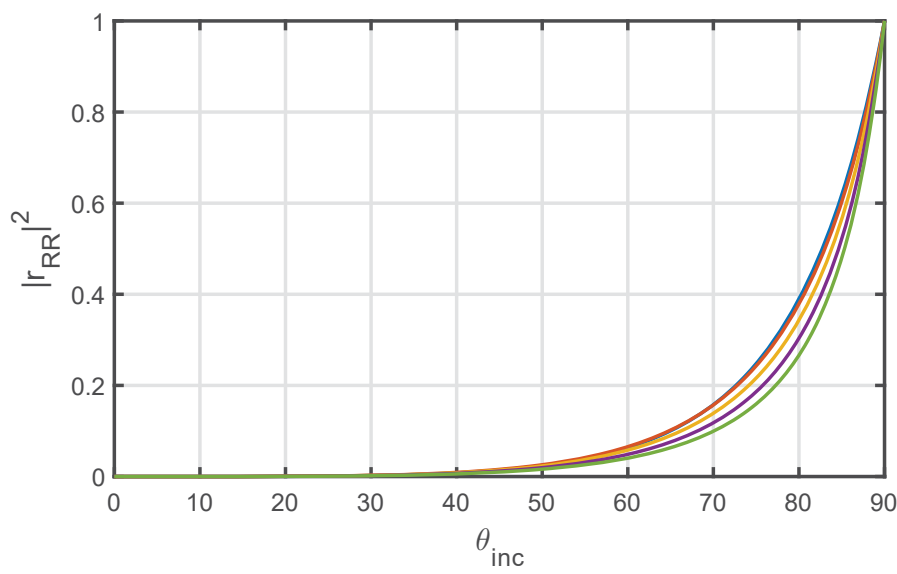

$\longrightarrow \mathrm{SM}=0-\mathrm{SM}=0.1-\mathrm{SM}=0.2-\mathrm{SM}=0.3-\mathrm{SM}=0.4$

(c)

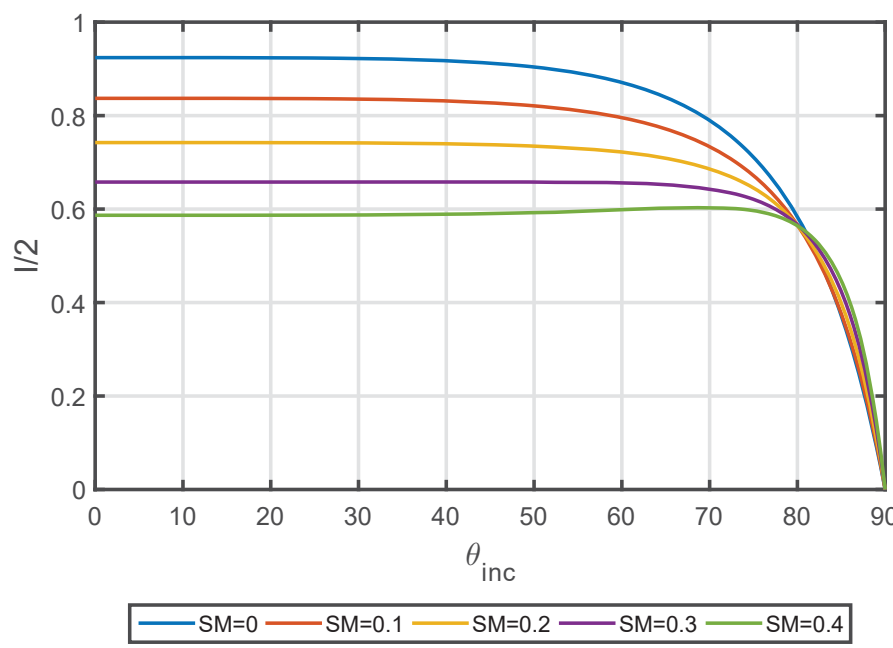

(e)

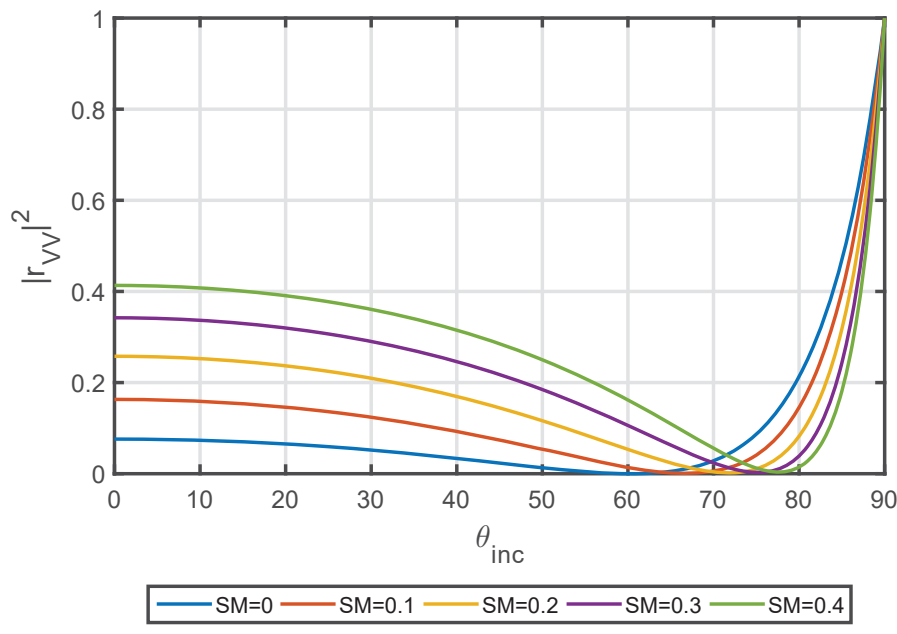

(b)

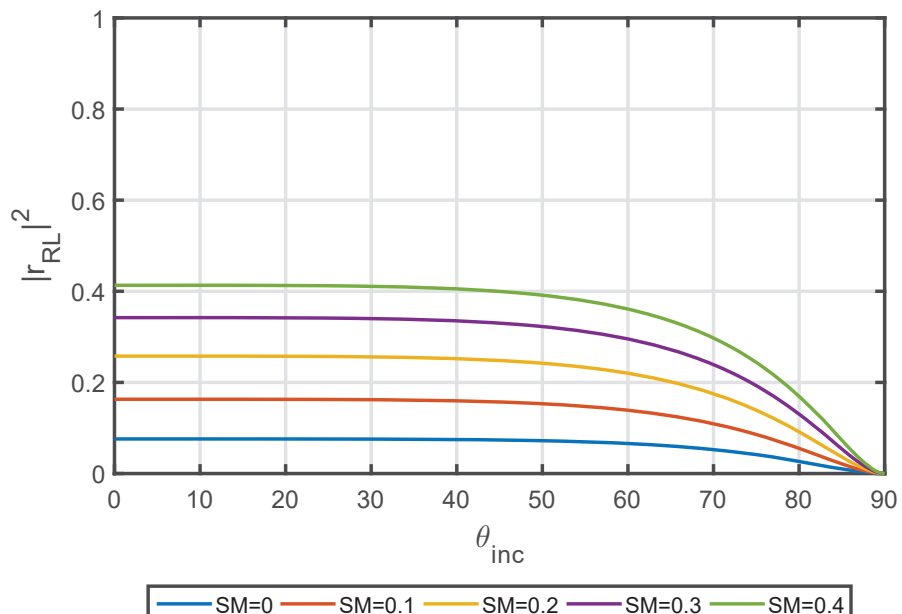

(d)

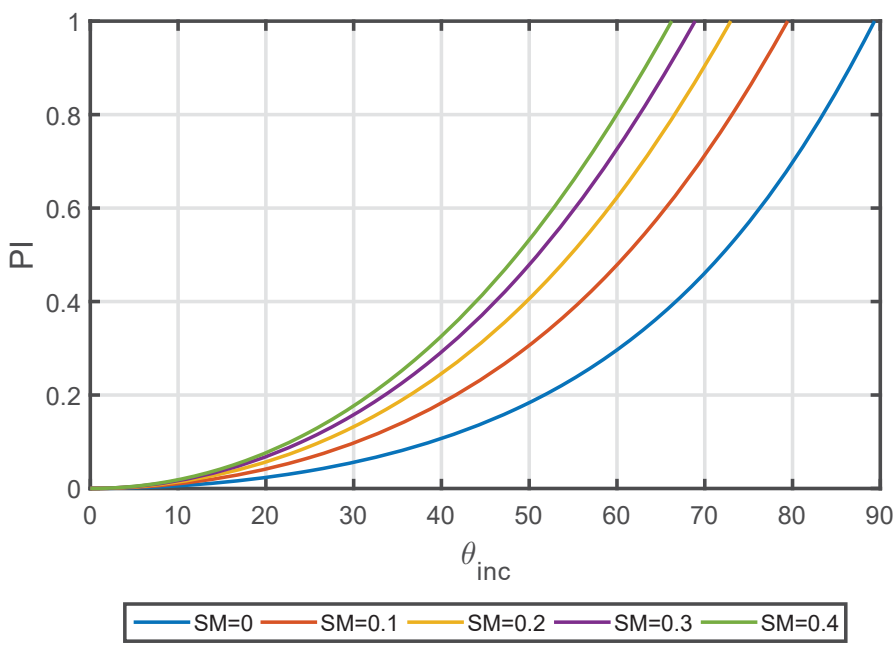

(f)

Fig. 1: Reflectivity curves for different polarization states as a function of incidence angle and soil moisture content (in $\mathrm{m}^{3} \mathrm{~m}^{-3}$ ) using Wang's dielectric constant model: (a) transmitted $\mathrm{H}$ and reflected $\mathrm{H}$, (b) transmitted V and reflected V, (c) transmitted RHCP and reflected RHCP, (d) transmitted RHCP and received LHCP, (e) normalized first Stokes parameter (I/2), and (f) PI. 


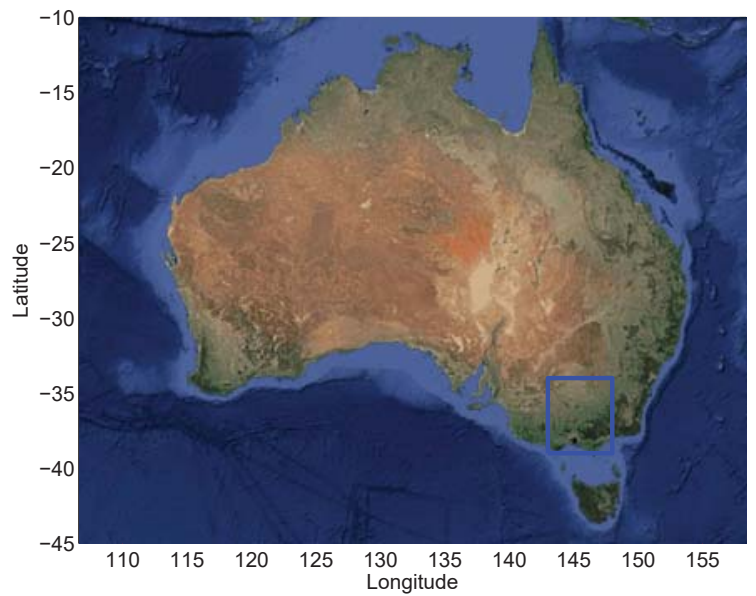

(a)

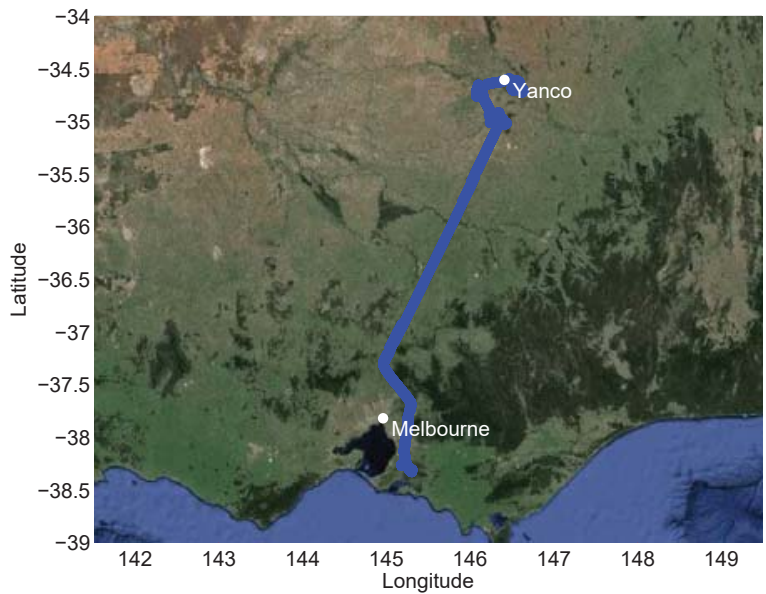

(b)

Fig. 2: Flight route followed for the three field campaigns in South-Eastern Australia: (a) Australian map with the field campaign region indicated/highlighted in blue, (b) Zoom of the field campaign region with the flight route in blue highlighting Melbourne's location and Yanco's location in white.

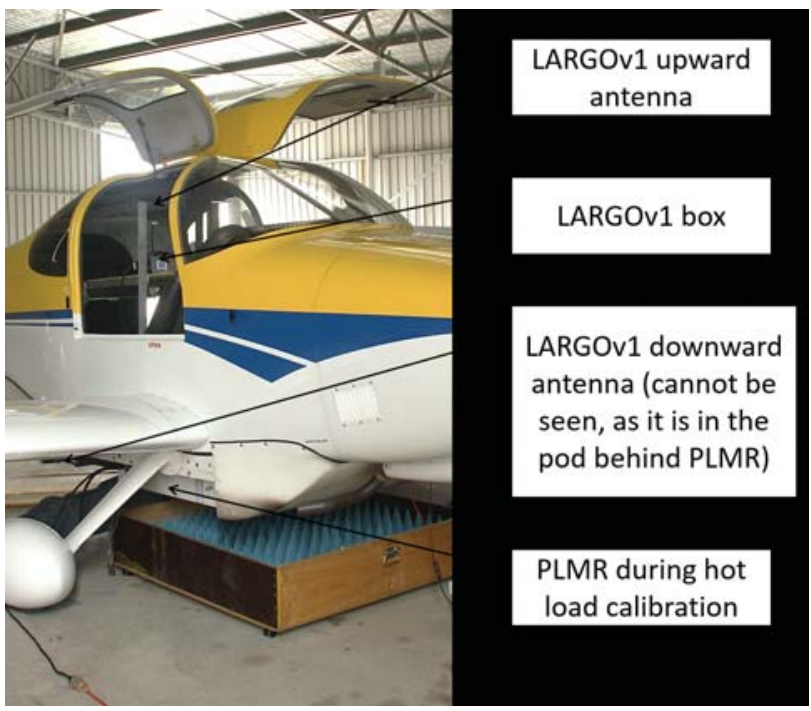

(a)

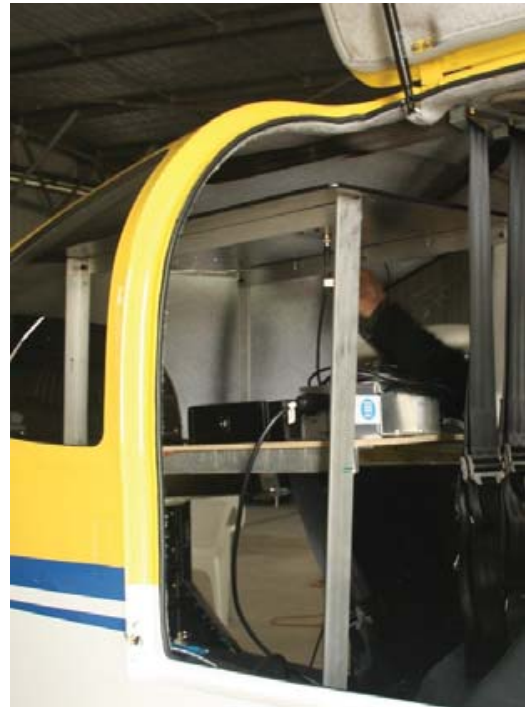

(b)

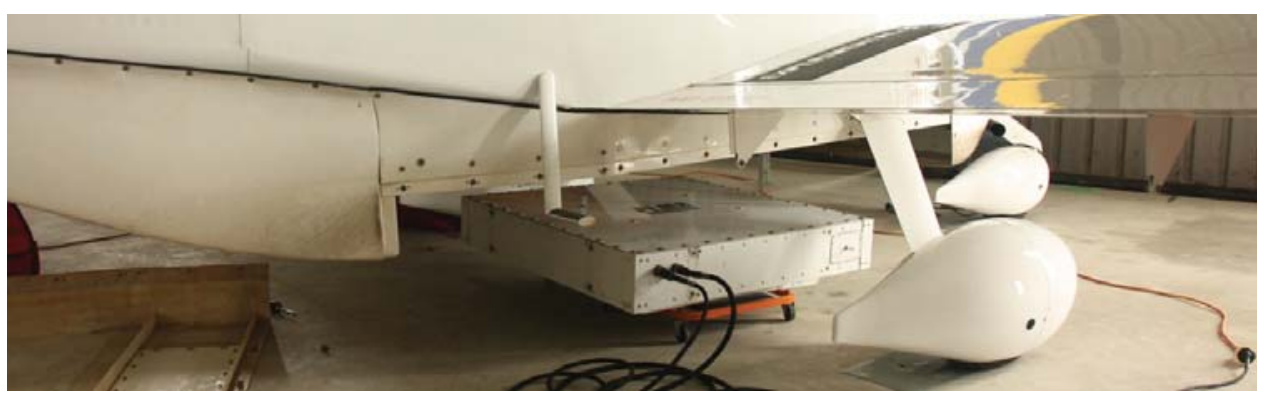

(c)

Fig. 3: Flight setup with the LARGO and PLMR instruments: (a) General set-up, (b) LARGO instrument zoomed with uplooking antenna connection, (c) PLMR instrument. 


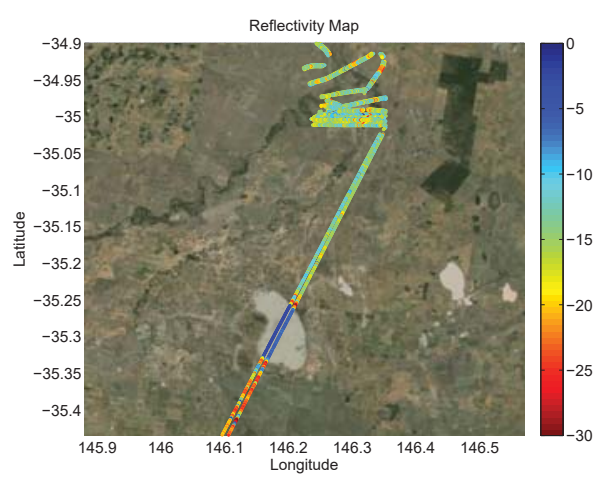

(a)

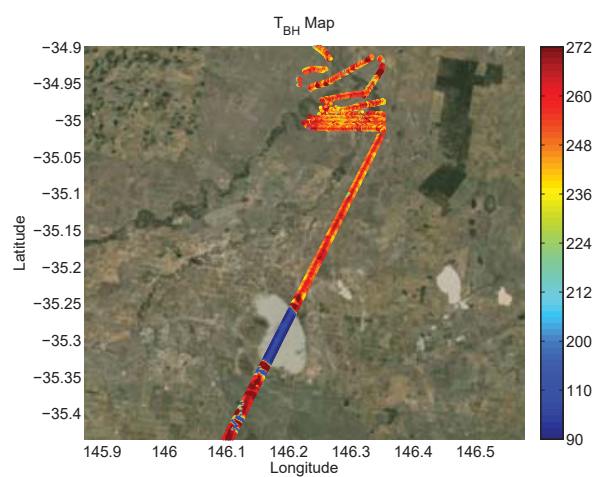

(d)

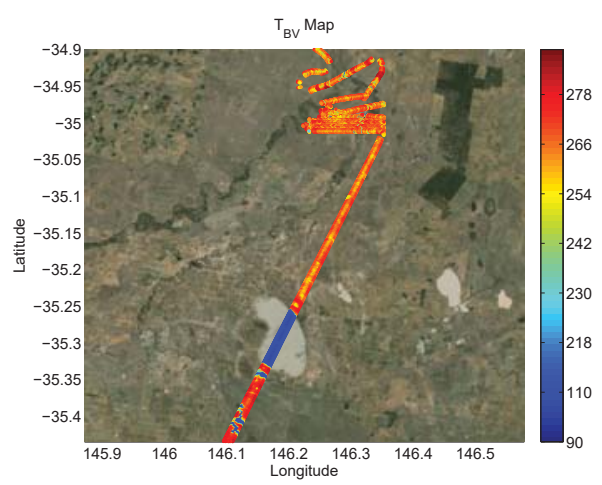

(g)

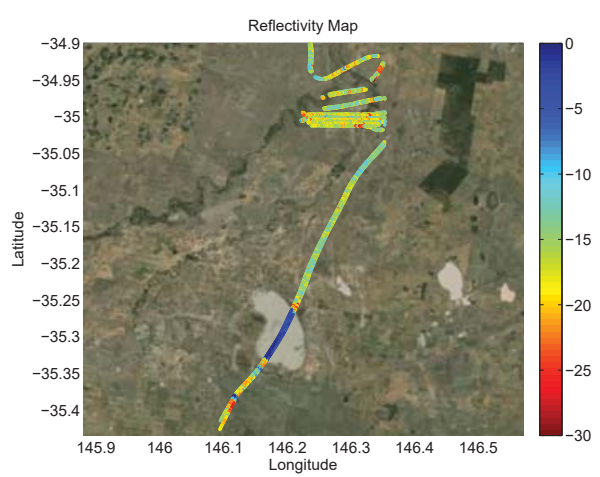

(b)

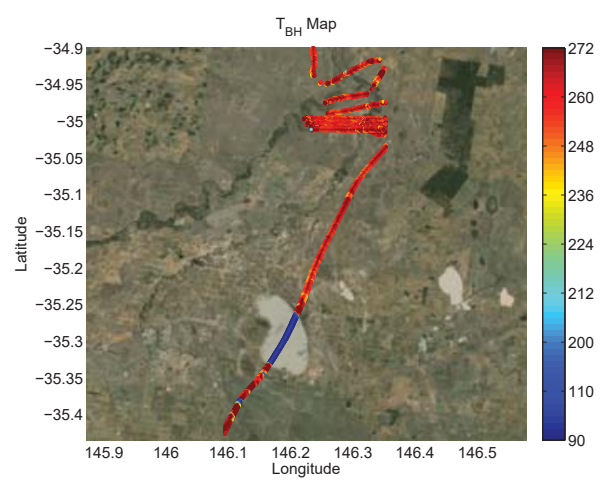

(e)

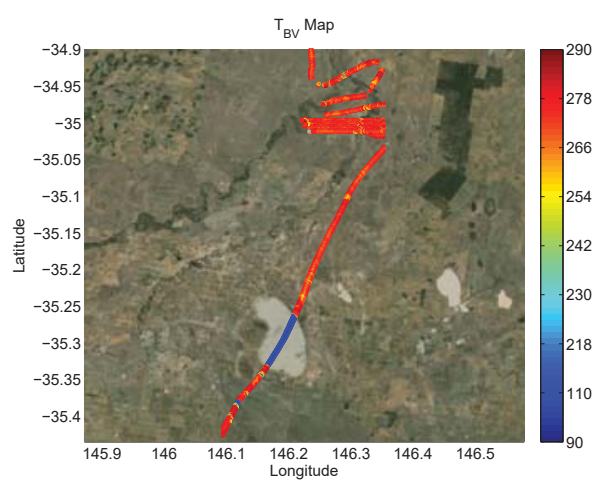

(h)

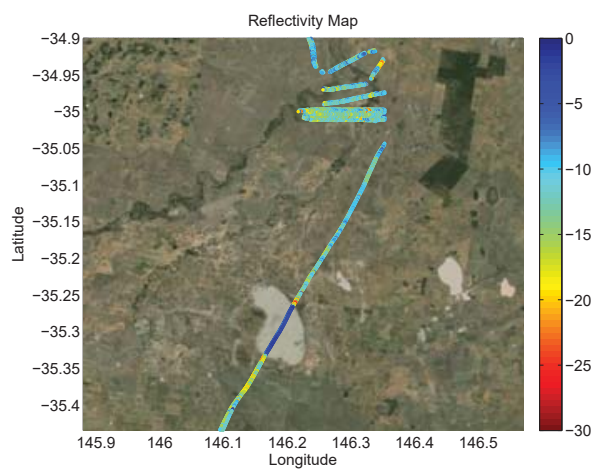

(c)

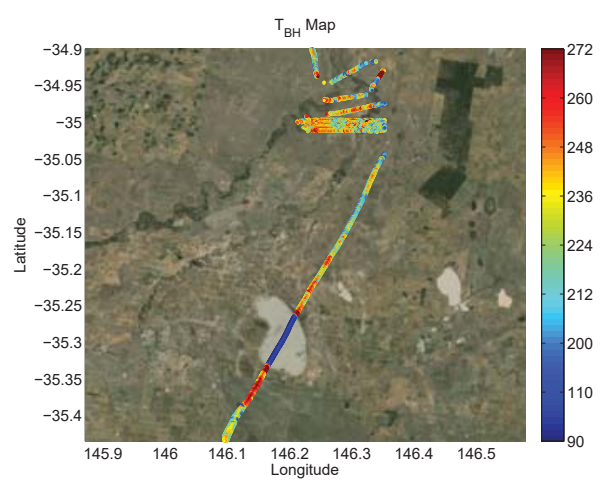

(f)

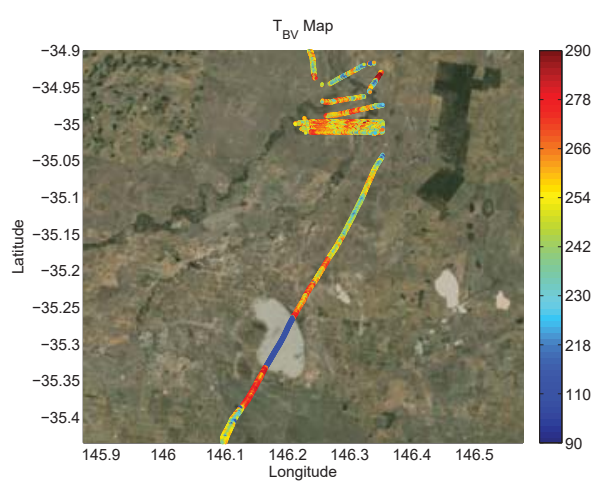

(i)

Fig. 4: Summary of the reflectivity and $\mathrm{T}_{B}$ maps for the three GELOz field campaigns for a sub-set of the field campaign: (a)-(c) Reflectivity maps for the first, second, and third flight respectively, (d)-(f) $\mathrm{T}_{B H}$ maps for the first, second, and third flight respectively, (g)-(i) $\mathrm{T}_{B V}$ maps for the first, second, and third flight respectively. 


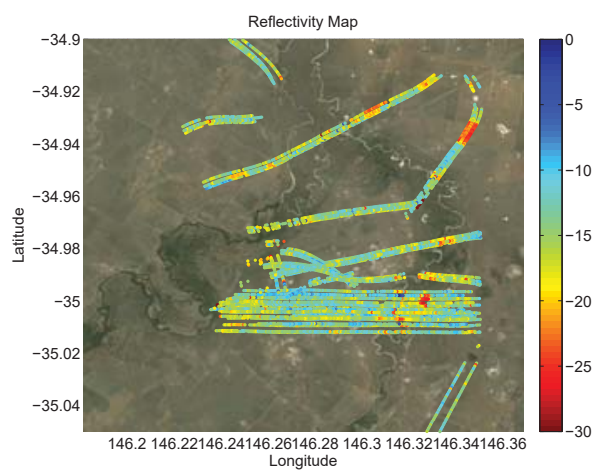

(a)

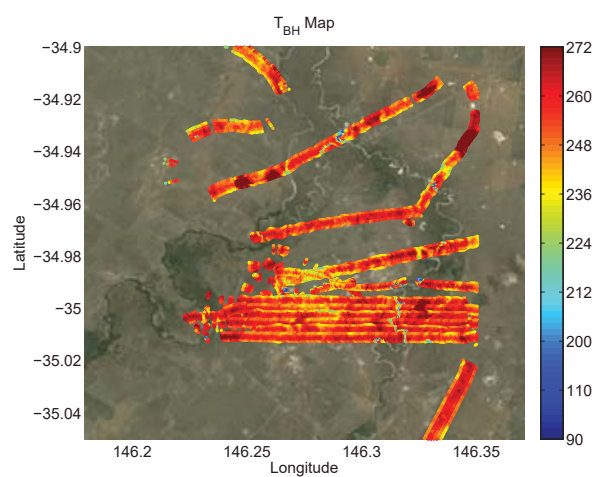

(d)

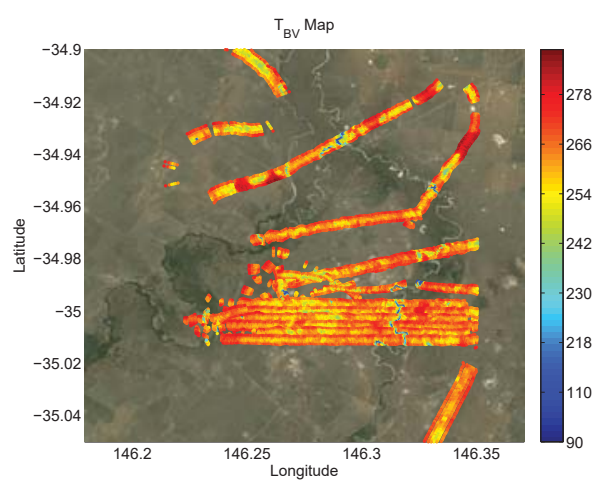

(g)

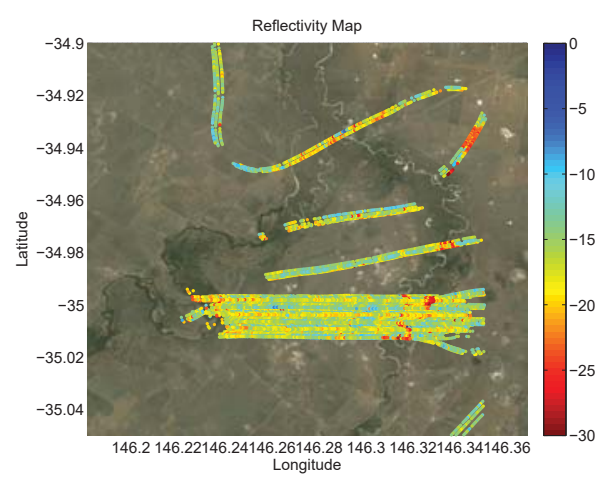

(b)

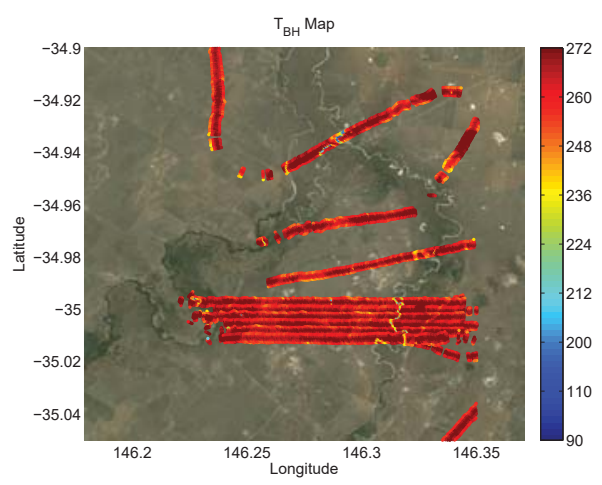

(e)

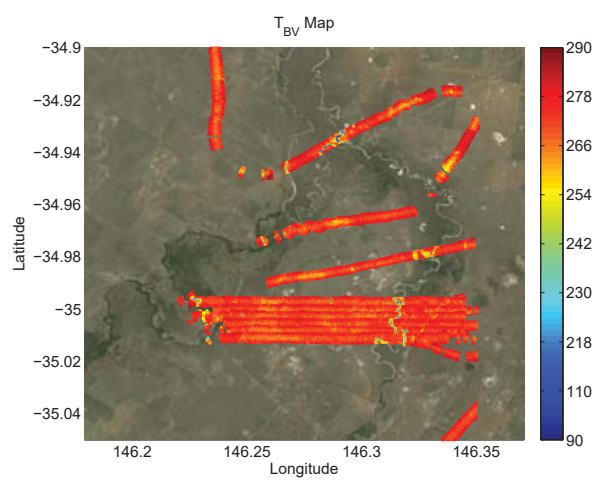

(h)

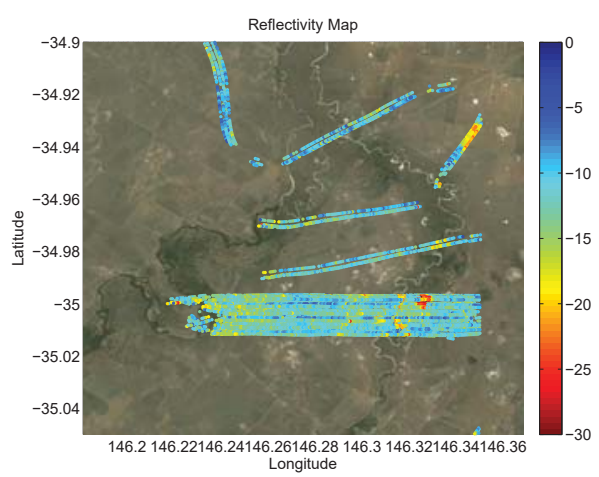

(c)

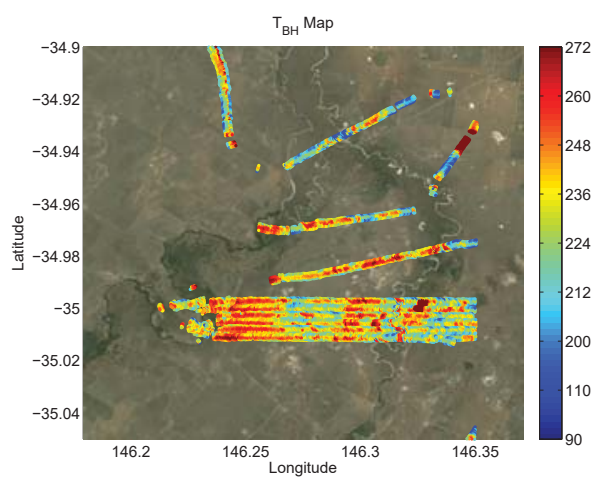

(f)

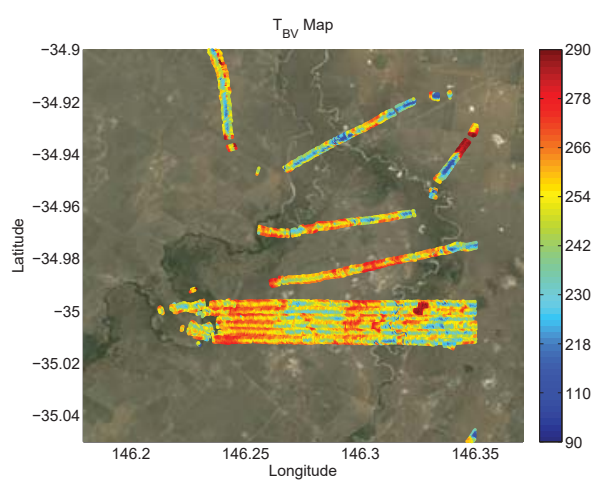

(i)

Fig. 5: Summary of the reflectivity and $\mathrm{T}_{B}$ maps for the three GELOz field campaigns over the grass-land area: (a)-(c) Reflectivity maps for the first, second, and third flight respectively, (d)-(f) $\mathrm{T}_{B H}$ maps for the first, second, and third flight respectively, (g)-(i) $\mathrm{T}_{B V}$ maps for the first, second, and third flight respectively. 


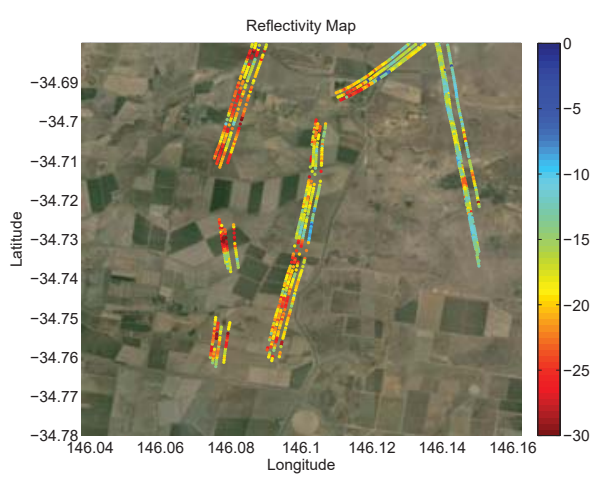

(a)

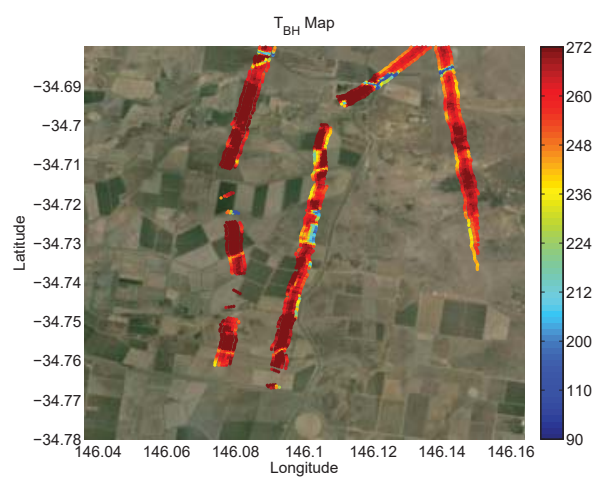

(d)

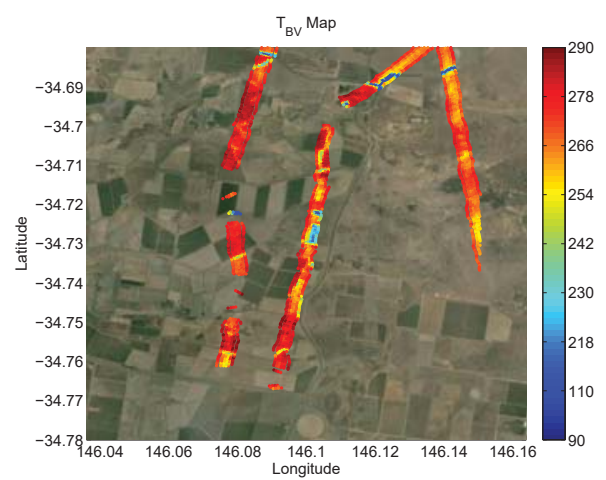

(g)

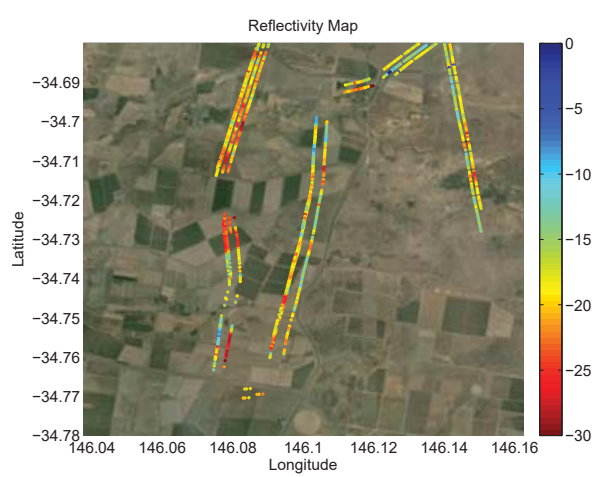

(b)

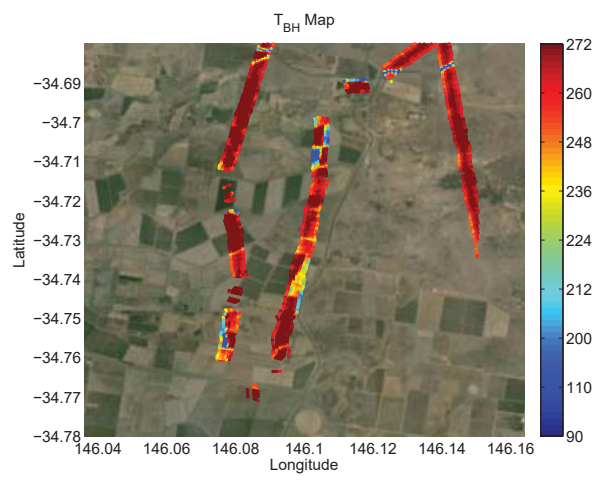

(e)

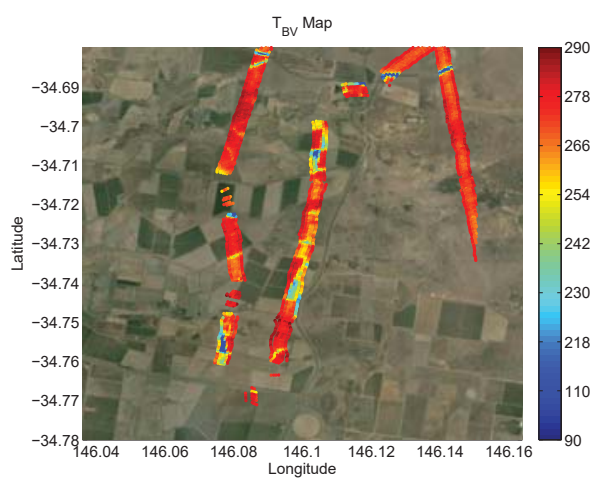

(h)

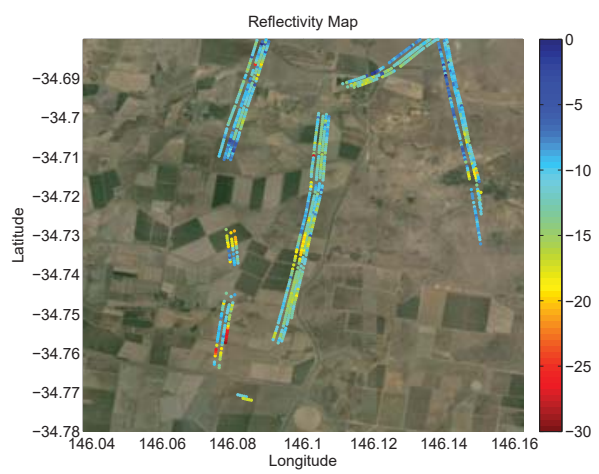

(c)

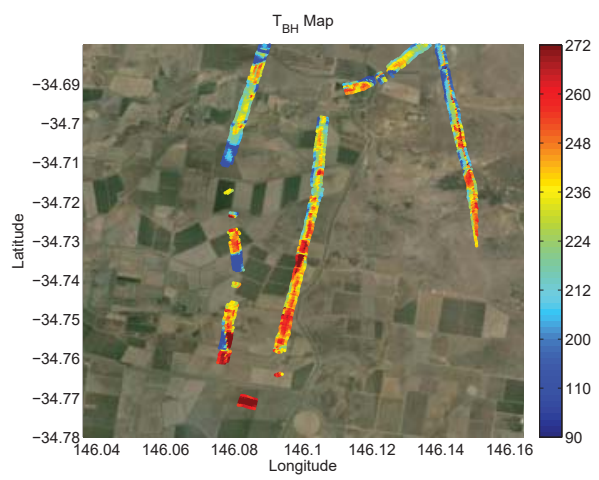

(f)

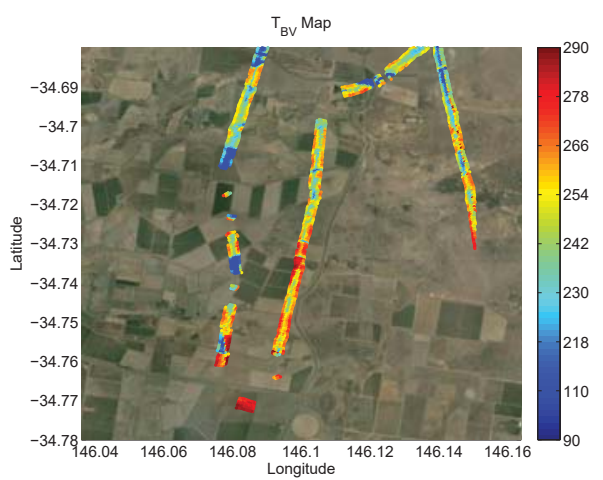

(i)

Fig. 6: Summary of the reflectivity and $\mathrm{T}_{B}$ maps for the three GELOz field campaigns over the crops area: (a)-(c) Reflectivity maps for the first, second, and third flight respectively, (d)-(f) $\mathrm{T}_{B H}$ maps for the first, second, and third flight respectively, (g)-(i) $\mathrm{T}_{B V}$ maps for the first, second, and third flight respectively. 


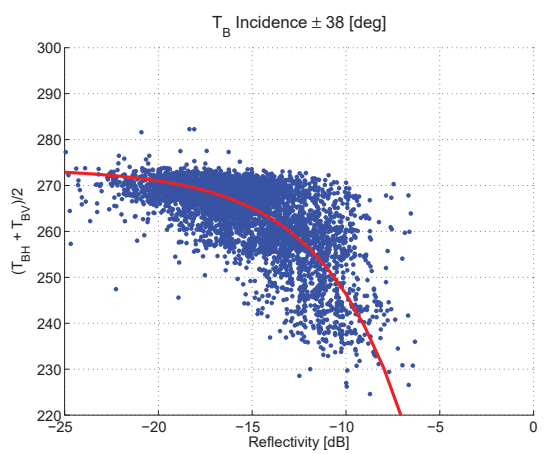

(a)

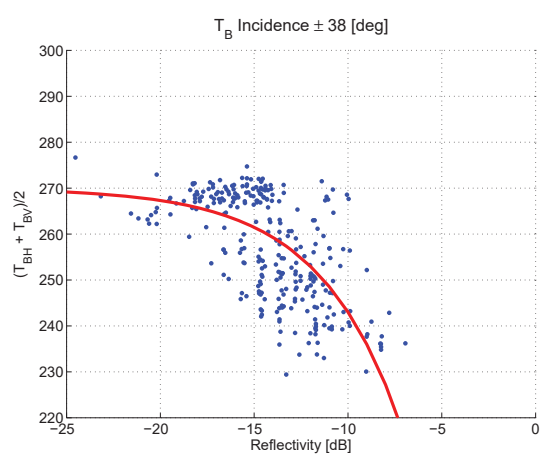

(d)

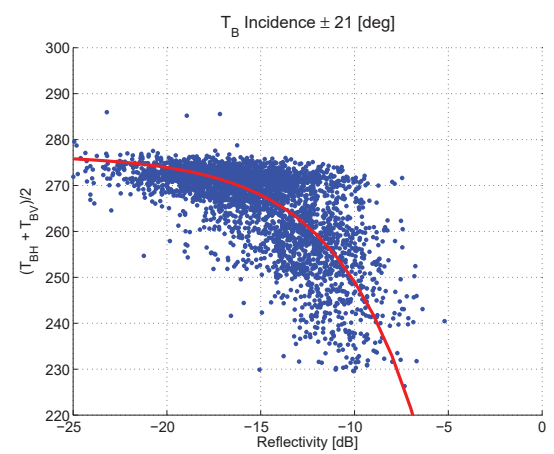

(b)

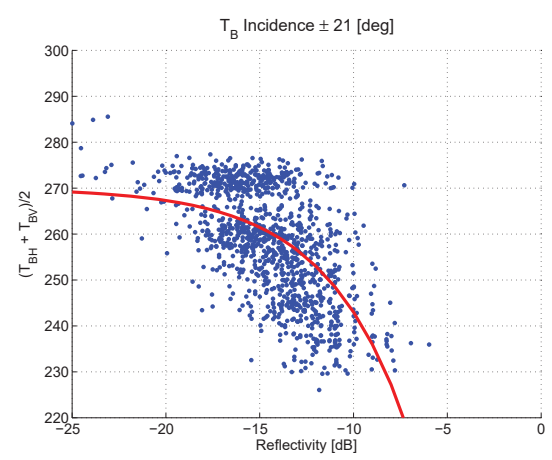

(e)

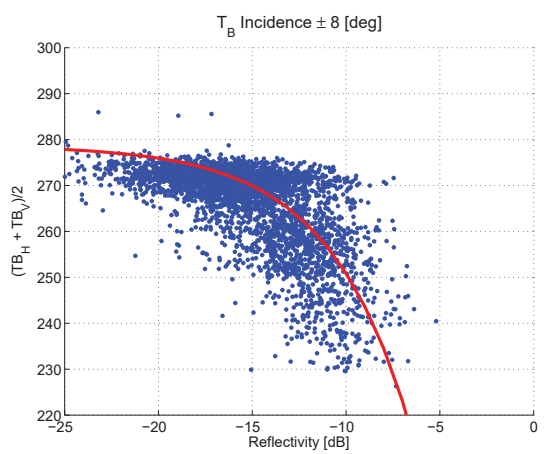

(c)

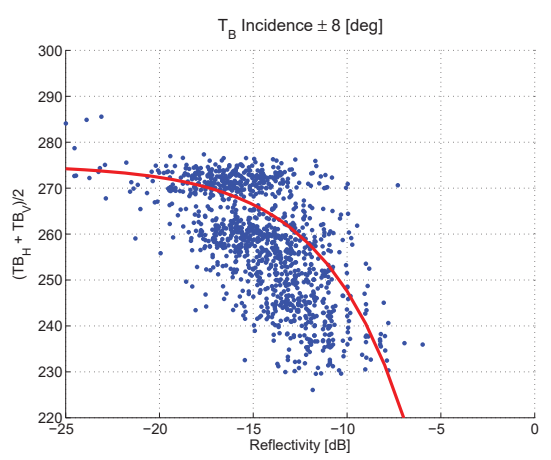

(f)

Fig. 7: Comparison between LARGO reflectivities and the first Stokes parameter divided by two for the grass-land regions. In (a)-(c) the reflectivity data corresponds to incidence angles ranging from $30^{\circ}$ to $50^{\circ}$. In (d)-(f) the reflectivity data corresponds to incidence angles lower than $30^{\circ}$. In (a),(d) PLMR data from the $\pm 38^{\circ}$ incidence angles beams is used. In (b),(e) PLMR data from the $\pm 21^{\circ}$ incidence angles beams is used. In (c),(f) PLMR data from the $\pm 8^{\circ}$ incidence angles beams is used. In red the best fit is presented. 


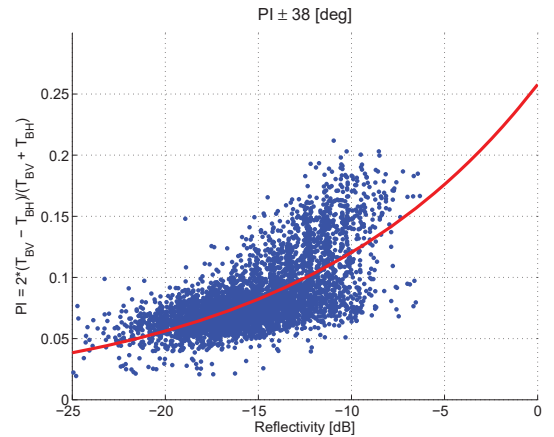

(a)

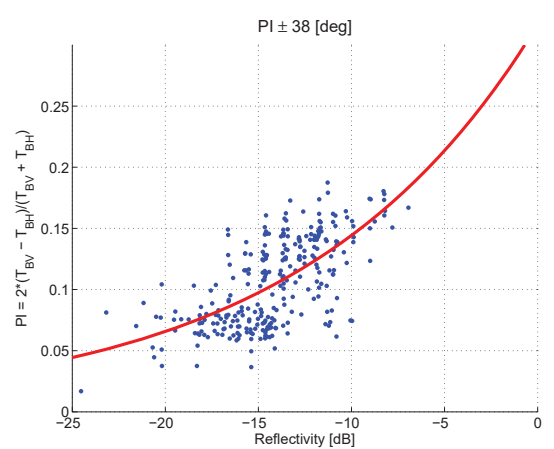

(d)

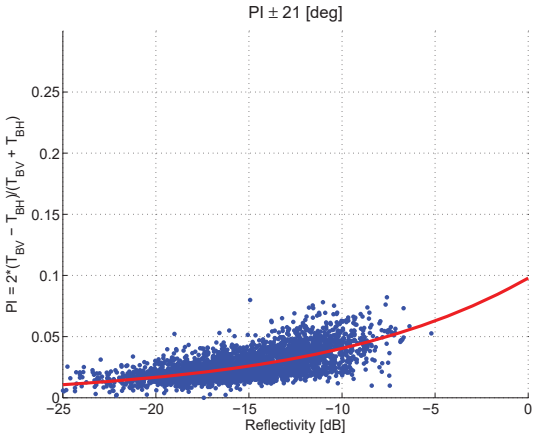

(b)

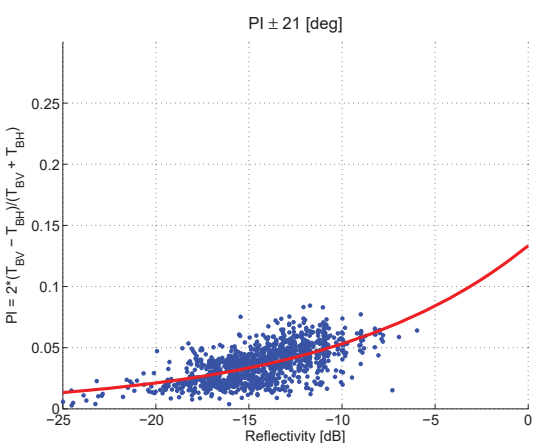

(e)

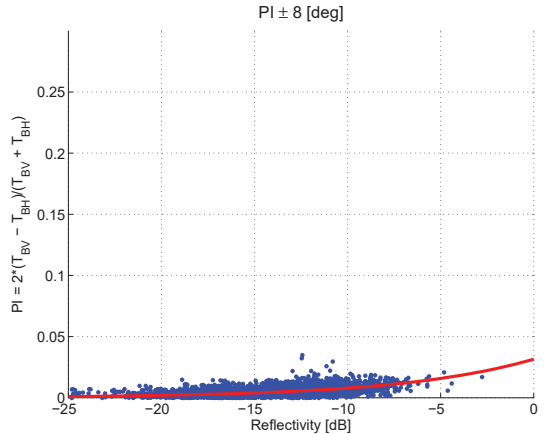

(c)

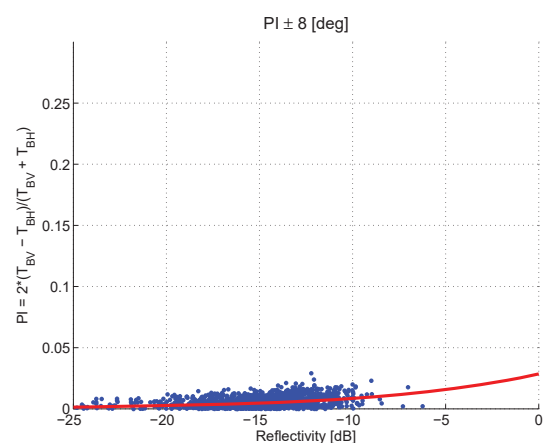

(f)

Fig. 8: Comparison between LARGO reflectivities and the PI for the grass-land regions. In (a)-(c) the reflectivity data corresponds to incidence angles ranging from $30^{\circ}$ to $50^{\circ}$. In (d)-(f) the reflectivity data corresponds to incidence angles lower than $30^{\circ}$. In (a),(d) PLMR data from the $\pm 38^{\circ}$ incidence angles beams is used. In (b), (e) PLMR data from the $\pm 21^{\circ}$ incidence angles beams is used. In (c),(f) PLMR data from the $\pm 8^{\circ}$ incidence angles beams is used. In red the best fit is presented. 


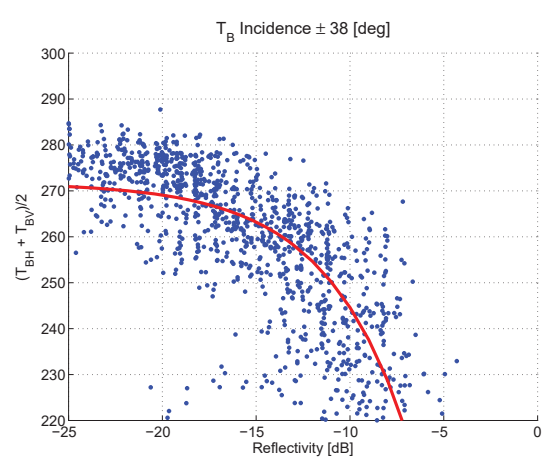

(a)

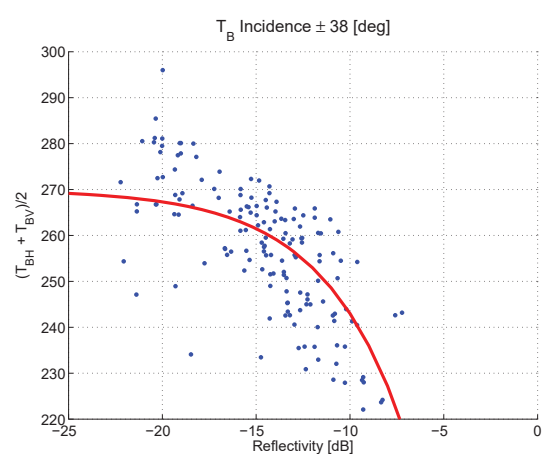

(d)

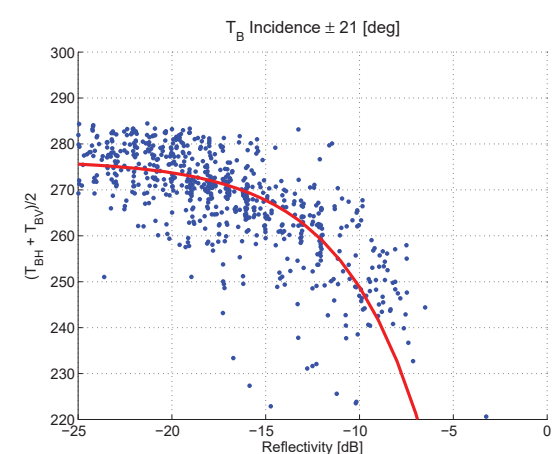

(b)

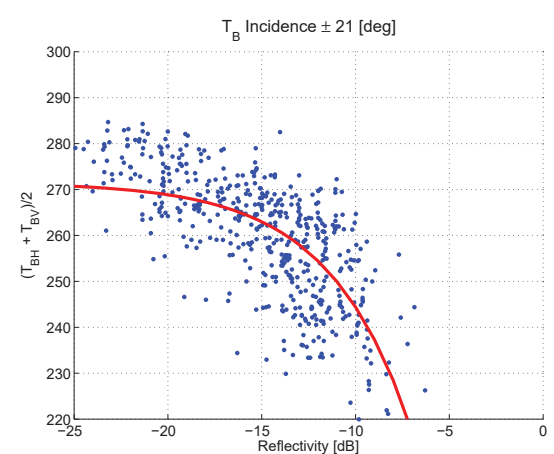

(e)

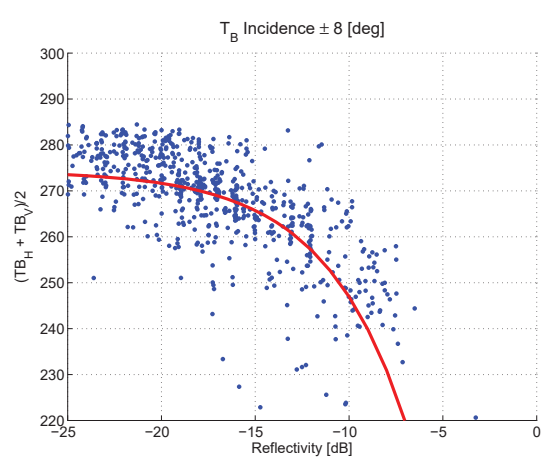

(c)

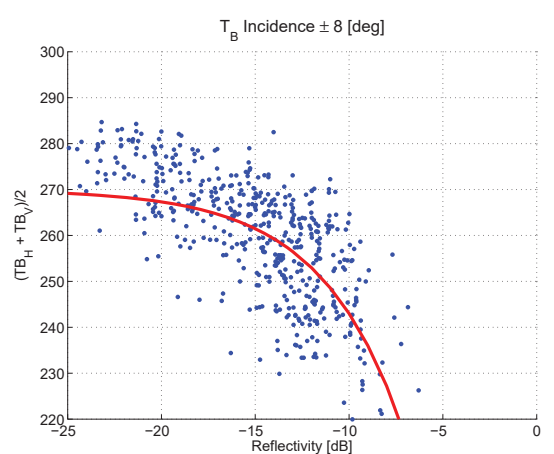

(f)

Fig. 9: Comparison between LARGO reflectivities and the first Stokes parameter divided by two for the crops region. In (a)-(c) the reflectivity data corresponds to incidence angles ranging from $30^{\circ}$ to $50^{\circ}$. In (d)-(f) the reflectivity data corresponds to incidence angles lower than $30^{\circ}$. In (a),(d) PLMR data from the $\pm 38^{\circ}$ incidence angles beams is used. In (b), (e) PLMR data from the $\pm 21^{\circ}$ incidence angles beams is used. In (c),(f) PLMR data from the $\pm 8^{\circ}$ incidence angles beams is used. In red the best fit is presented. 


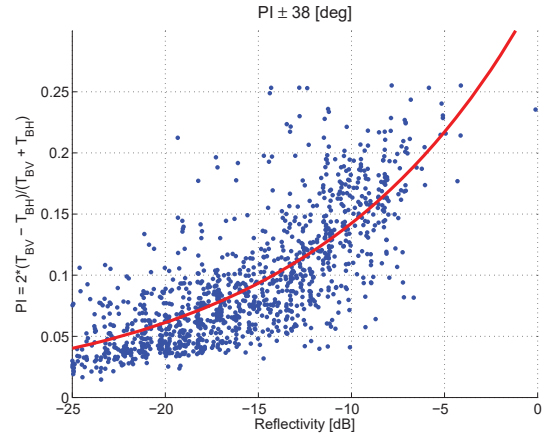

(a)

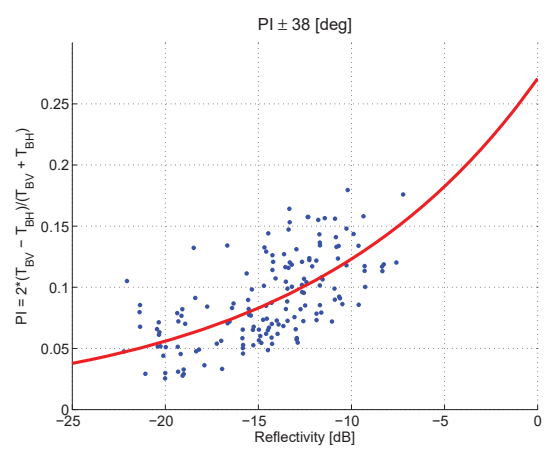

(d)

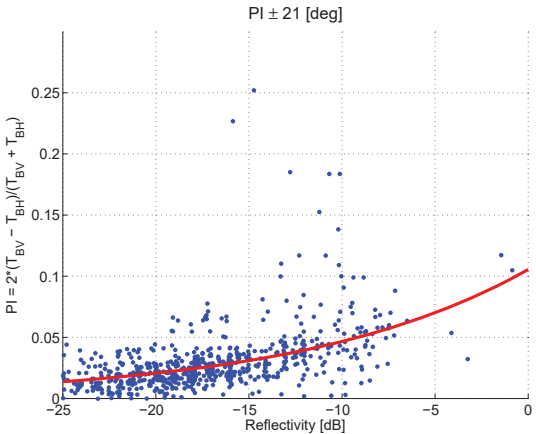

(b)

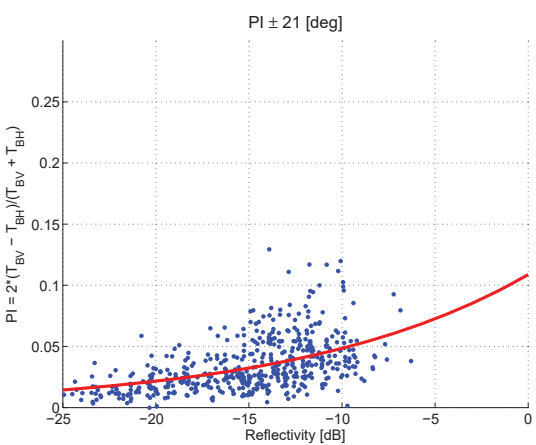

(e)

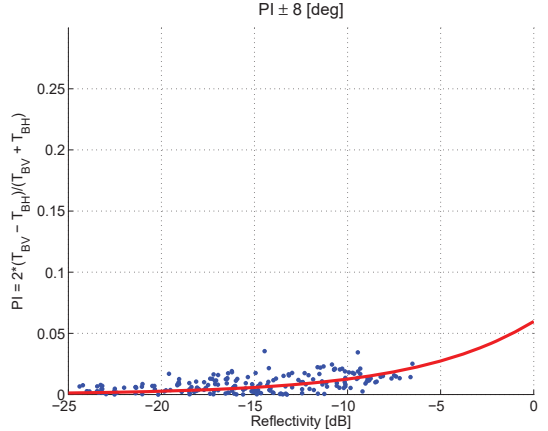

(c)

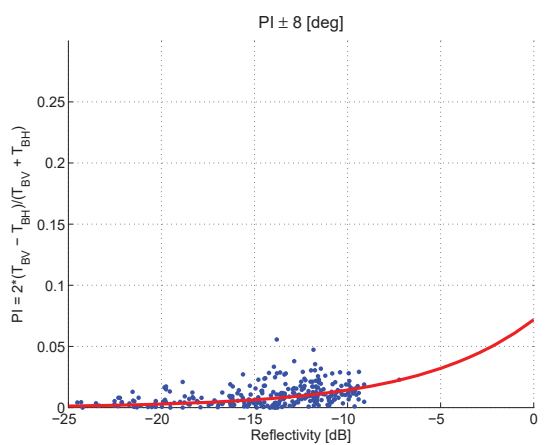

(f)

Fig. 10: Comparison between LARGO reflectivities and the PI for the crops region. In (a)-(c) the reflectivity data corresponds to incidence angles ranging from $30^{\circ}$ to $50^{\circ}$. In (d)-(f) the reflectivity data corresponds to incidence angles lower than $30^{\circ}$. In (a),(d) PLMR data from the $\pm 38^{\circ}$ incidence angles beams is used. In (b),(e) PLMR data from the $\pm 21^{\circ}$ incidence angles beams is used. In (c),(f) PLMR data from the $\pm 8^{\circ}$ incidence angles beams is used. In red the best fit is presented. 


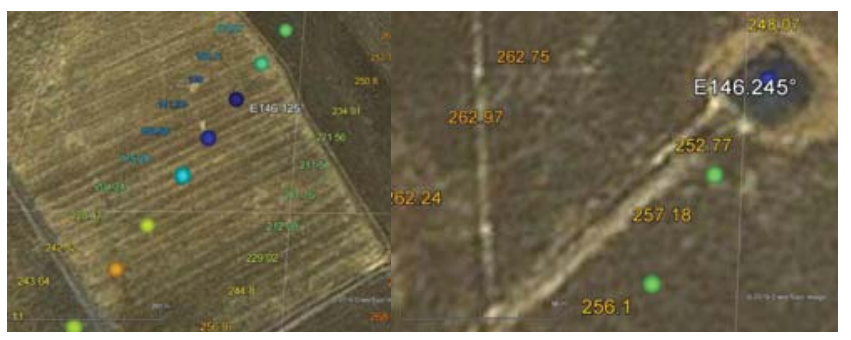

(a)

(b)

Fig. 11: Effect of the pixel size in the comparison among reflectivity and microwave radiometry data. 